\title{
Vaccination Intentions Generate Racial Disparities in the Societal Persistence of COVID-19
}

\section{Yanchao Wang}

Northeastern University

Alina Ristea

Northeastern University

Mehrnaz Amiri

Northeastern University

Dan Dooley

Boston Public Health Commission

\section{Sage Gibbons}

Northeastern University

Hannah Grabowski

University of Massachusetts Boston

Lee Hargraves

University of Massachusetts Boston

Nikola Kovacevic

University of Massachusetts Boston

Anthony Roman

University of Massachusetts Boston

Russell K. Schutt

University of Massachusetts Boston

Jianxi Gao

Rensselaer Polytechnic Institute

Qi Wang

Northeastern University

Daniel T. O'Brien ( $\nabla$ d.obrien@northeastern.edu )

Northeastern University

\section{Research Article}

Keywords: Continued Infection Rates, Herd Immunity, Persuasion, Messaging, Resistance to Vaccinate

Posted Date: April 14th, 2021 
DOI: https://doi.org/10.21203/rs.3.rs-353532/v1

License: (c) (1) This work is licensed under a Creative Commons Attribution 4.0 International License. Read Full License 


\section{Title: Vaccination Intentions Generate Racial Disparities in the Societal Persistence of COVID-19}

Authors: Yanchao Wang ${ }^{1} \dagger$, Alina Ristea ${ }^{2,3} \dagger$, Mehrnaz Amiri ${ }^{2,3}$, Dan Dooley ${ }^{4}$, Sage Gibbons ${ }^{2,3}$, Hannah Grabowski ${ }^{5,6}$, Lee Hargraves ${ }^{5}$, Nikola Kovacevic ${ }^{5}$, Anthony Roman ${ }^{5}$, Russell K. Schutt ${ }^{6,7}$, Jianxi Gao ${ }^{8}$, Qi Wang ${ }^{1,2 *}$, Daniel T. O'Brien ${ }^{2,3 *}$

\section{Affiliations:}

${ }^{1}$ Department of Civil and Environmental Engineering, Northeastern University, Boston, MA, 02120, United States.

${ }^{2}$ School of Public Policy and Urban Affairs, Northeastern University, Boston, MA, 02120, United States.

${ }^{3}$ Boston Area Research Initiative, Northeastern University, Boston, MA, 02120, United States.

${ }^{4}$ Boston Public Health Commission, Boston, MA, 02118, United States.

${ }^{5}$ Center for Survey Research, University of Massachusetts Boston, Boston, MA, 02125, United States.

${ }^{6}$ Department of Sociology, University of Massachusetts Boston, Boston, MA, 02125, United States.

${ }^{7}$ Beth Israel Deaconess Medical Center, Boston, MA, 02215, United States.

${ }^{8}$ Department of Computer Science, Rensselaer Polytechnic Institute, Troy, New York, 12180, United States.

$\dagger$-These authors contributed equally to this work.

*Corresponding authors. Emails: d.obrien@neu.edu, q.wang@neu.edu

Abstract: We combined survey, mobility, and infections data in greater Boston, MA to simulate the effects of racial disparities in the inclination to become vaccinated on continued infection rates and the attainment of herd immunity. The simulation projected marked inequities, with communities of color experiencing infection rates 3 times higher than predominantly White communities and reaching herd immunity 45 days later on average. Persuasion of individuals uncertain about vaccination was crucial to preventing the worst inequities but could only narrow them so far because $1 / 5^{\text {th }}$ of Black and Latinx individuals said that they would never vaccinate. The results point to a need for well-crafted, compassionate messaging that reaches out to those most resistant to the vaccine.

One-Sentence Summary: In a survey-based simulation, communities of color took 45 days longer than White communities to attain herd immunity. 


\section{Main Text:}

Ever since the World Health Organization declared COVID-19 to be a global pandemic on 11 March 2020, vaccination has been the light at the end of the tunnel. Following an unprecedented development effort by the biotech industry, the first vaccines are now becoming available in some countries for health-care workers and the most at-risk. The United States, United Kingdom, and many other nations have begun to distribute vaccines to high-risk groups and plan to extend distribution to the general public in the spring. This process will curtail the rate of infection and is expected eventually to eliminate infections by creating herd immunity. But an available vaccine does not automatically create herd immunity. If a sufficient fraction of the population does not choose to be vaccinated $(1,2)$, substantial numbers of people will remain susceptible and infections will persist.

A series of recent surveys have revealed that $\sim 30-40 \%$ of Americans are hesitant to get vaccinated against COVID-19 (3-5); this mirrors results in other countries (6-10). Some respondents are worried about receiving a vaccine before seeing more widespread evidence that it is effective and has few side-effects $(5,7,9)$. For example, a December 2020 KFF COVID-19 Vaccine Monitor survey reported that among the $27 \%$ of the U.S. population likely to not get the vaccine, $59 \%$ were worried about side effects and 55\% did not trust the government to make sure that the vaccine is safe and effective (11). Others stated that they are opposed to being vaccinated altogether, following a growing trend in American society to reject vaccines as having dangerous side effects $(12,13)$. Resistance to COVID-19 vaccination is particularly pronounced among Black Americans, who cite a long history of discrimination and mistreatment at the hands of medical professionals $(14,15)$. 
The various objections to vaccination and their uneven distribution across communities pose a major challenge for the pursuit of vaccine-based herd immunity. Of particular concern, differences between communities in willingness to be vaccinated will multiply the risks faced by residents and reduce the chances of achieving herd immunity locally for all. Specifically, if too few Black and Latinx individuals choose to be vaccinated, communities with many Black and Latinx residents will remain vulnerable to infection at disproportionate rates while communities that are predominantly White and Asian approach herd immunity. Such a disparate result would be yet another racial inequity in a pandemic that has already had a glaringly disparate impact on health and finances in Black and Latinx communities (16-20). Further, communities are not islands unto themselves, and intermixing through the daily movements of individuals have been critical in explaining infection transmission across regions (21-26). As such, if any community in a region fails to achieve a sufficient level of vaccination, it could harbor infections that still pose a risk to unvaccinated individuals in other communities through mobility-based transmission.

The current study evaluates the inequities that might arise from differential willingness to be vaccinated across a single metro region. We use a traditional SIR (susceptibility-infectionrecovery) model for simulating the evolution of an infectious disease within a community, applied across the ZIP codes of Boston, MA, and the surrounding municipalities in the greater Boston area (collectively referred to as "communities" from hereon). We further inform these models using mobility data generated by cell phones to track how movement between communities could further spread the disease (21-26). We incorporate into these models an additional set of parameters for the gradual rollout of a vaccine, which removes individuals from a community's susceptible population at an assumed rate of effectiveness, based on clinical trials (27). We simulate the vaccination rollout as if it had occurred October-December, 2020. This 
matches the proposed three-month vaccination process for the general population that many leaders are promising and allows us to leverage historical mobility and infections data and, as has been demonstrated by other simulation studies of vaccination (28), permits us a clear counterfactual against which we can compare the introduction of vaccination.

The study is designed to address four main research questions. First, we simulate both the global and community-specific rollout of vaccines, revealing at what point the process would be expected to hit a "bottleneck," where supply outstrips willing recipients, and whether this milestone arrives at different times across communities. This will be crucial to leaders seeking to manage vaccine supply. Second, we quantify the anticipated impact of racial differences in vaccination hesitancy, which are largely attributable to historical inequities in medical treatment. To do so we use results from three recent surveys that separated responses by race to approximate willingness to vaccinate in each community. Third, there is evidence that those who are uncertain about receiving a new medical procedure, including vaccinations, often wait until others that they know have done so with few negative side effects (29-31). In order to examine the both the impact and limitations of this process, we include a "persuasion" rate (or "imitation" factor; 32, 33) by which individuals who were uncertain if they would get vaccinated can eventually decide to do so as the proportion of those vaccinated in their community increases. Fourth, a major concern is that slow uptake of vaccination in one community can undermine herd immunity in neighboring areas via mobility-based exposure. Here we will be able to evaluate this proposition. 


\section{Results}

\section{Vaccination}

In three independent surveys of Boston and Massachusetts residents in the fall of 2020, 49.6\% of respondents said that they planned to get the COVID-19 vaccine, and $8.8 \%$ said that they did not; the remaining $41.6 \%$ were uncertain. These responses featured prominent disparities by race, however. On the low end, $6.6 \%$ of White respondents and $1.8 \%$ of Asian respondents said they would definitely not get the vaccine, compared to $21.7 \%$ of Black and $20 \%$ of Latinx respondents (see Figure 1a). We combined these ratios with the racial composition of communities to estimate the percentage of residents in each who planned to get vaccinated, did not plan to, and who were uncertain. This revealed stark differences across communities, with municipalities in the region varying between $33.9 \%$ and $54.1 \%$ of the population saying they would definitely get vaccinated, and between $5.4 \%$ and $17.2 \%$ saying they definitely would not; the same ranges indicated slightly less receptivity of vaccines in Boston's ZIP codes, which has a higher Black and Latinx population than most surrounding municipalities (definitely will: $28.2 \%$ - 52.1\%; definitely will not: 5.1\% - 19.8\%; sees Figure 1b, Figure S1a-c).

We simulated the impact of vaccination across communities by incorporating it into an SIR-mobility model with parameters approximating transmission and recovery rates based on actual case numbers for October-December 2020. We also assume the $95 \%$ efficacy of the vaccine reported by the initial clinical trials (27) and that vaccination will occur at the rate of $8.25 \%$ of the population per week, following the goal of complete vaccination over a twelveweek (3-month) period. The model also allowed for those uncertain about the vaccine to be persuaded, contingent on the likelihood of seeing others in their neighborhood who had been vaccinated and presumably not seen adverse side effects (31). To maintain a true counterfactual, 
all comparisons of outcomes are made against the results of the same model without vaccination as a facsimile for the actual events of this time period.

Figure 2a depicts a steady increase over the three-month period in the proportion of people who were vaccinated across the region, reaching $75 \%$. In late November, however, the vaccination process hit a bottleneck (mean $=53$ days into simulation). It had exhausted all individuals who either were willing to be vaccinated at the outset or were persuaded to that point, as indicated by the blue line reaching zero. As a result, vaccination from then on was dependent on those additional individuals who were persuaded in each week, which was less than the rate at which vaccination was possible. This created the kink in the red line, indicating a slowed vaccination process from that point on, explaining why the simulation did not successfully vaccinate $100 \%$ of the population after 12 weeks, despite having the capacity to do so.

The bottleneck in vaccination did not occur at the same time in all communities (see Figures $2 \mathrm{~b}-\mathrm{c})$. For purpose of comparison here and moving forward, we divide communities into those that are predominantly White ( $>80 \%$ White residents; $51 \%$ of communities), have high Black-Latinx populations ( $>20 \%$ Black and Latinx residents; $17 \%$ of communities), and those that are neither (32\% of communities). For predominantly White communities, the bottleneck was reached at the very end of November (mean $=57^{\text {th }}$ day). Meanwhile, in communities with high Black-Latinx populations the same milestone occurred before November 15 th $\left(\right.$ mean $=42^{\text {nd }}$ day). Because this date was reached earlier, the lower proportion of vaccinated residents at that time meant the power of persuasion was also diminished, meaning fewer additional people were persuaded each week thereafter than in predominantly White communities. This further exacerbated disparities in cumulative vaccinations. By the end of the simulation, residents in predominantly White communities were consistently $80 \%$ vaccinated whereas those living in 
high Black-Latinx populations were $71 \%$ vaccinated, though there were communities with rates of vaccination as low as $59 \%$.

\section{Infection Rates}

The impacts of vaccination, including disparities in uptake across communities, were evident in the corresponding evolution of infection rates. As shown in Figure 3a, infection rates kept pace with the no-vaccination scenario until mid-October, which is when vaccination began to substantially lower the population susceptible to infection. Over the following week or so, infection rates started to decrease, eventually nearing zero infections. To wit, $99 \%$ of communities had more than one case per 100 without vaccination, whereas no community was above 0.75 cases per 100 with vaccination.

The growth curve for infection rates under vaccination was consistent across communities of different racial composition, though with some noteworthy variations. First, the absolute drop in infection rates with vaccination was greater in communities of color, seemingly because they had much higher levels of infection in the no-vaccine scenario. In other words, vaccination held the greatest absolute benefit for communities harder hit by the virus. The second difference, however, was how close they came to herd immunity. Predominantly White communities nearly reached zero infections ( $3^{\text {rd }}$ quartile $=0.10$ cases per 100 residents). Meanwhile, communities with high Black-Latinx populations failed to reach this point, averaging 0.27 infections per 100 residents at the end of the simulation (Figures 3a-c).

A series of linear regression models confirmed the racial disparities in infection rates under the vaccination scenario (see Table 2 for all parameters). Communities with greater Black 
and Latinx populations had higher infection rates at the conclusion of the simulation (\% Black: B $=0.30, p<.001 ; \%$ Latinx: $\mathrm{B}=0.54, p<.001)$. Even when we controlled for expected infection rates, as drawn from the no-vaccine scenario, these racial disparities persist, meaning that differential uptake of the vaccine played a consequential role in cross-community variations in infection (\% Black: $\mathrm{B}=0.26, p<.001 ; \%$ Latinx: $\mathrm{B}=0.26, p<.001)$.

\section{Achieving Herd Immunity}

Moving beyond infection rates, did communities reach the goal of herd immunity via vaccination? We defined herd immunity as the point at which a community effectively eliminated the virus locally (i.e., $<1$ infection; the model permits fractions of infections). We found that only $27 \%$ of communities had reached herd immunity by this definition at the end of the simulation. We thus extended the simulation for three additional months (simulating mobility based on historical data; see Methods for more). An additional 52\% of communities achieved herd immunity in the fourth month of the extended simulation ( $80 \%$ cumulative), and all but one remaining community achieved herd immunity in the fifth month, which reached it shortly thereafter (see Figures 3d-e). The average community reached herd immunity on day 103 of the simulation.

Differences in achieving herd immunity again reflected stark disparities by race. Only $14 \%$ of communities with high Black-Latinx populations saw herd immunity before the fifth month of the simulation, whereas $99 \%$ of predominantly White communities had achieved herd immunity by this time. To reiterate, all predominantly White communities achieved herd immunity before any community with a high Black-Latinx population, some by nearly two 
months. The average difference in achieving herd immunity between these two sets of communities was 44 days ( 89 days and 134 days into the simulation).

\section{Mobility-based Exposure}

Mobility-based exposure - that is, the quantification of a community's potential exposure to infection via cross-community travel— has been a central component of models of the transmission of COVID (21-26) and we included it in our own. Unsurprisingly, when added to the previous regressions, mobility-based exposure in a community at the end of the simulation independently predicted higher infection rates, albeit with an effect size considerably lower than those of racial composition ( $\beta=0.22, p<.001$; see Table 2 for all parameters). The inclusion of mobility-based exposure in the model did not meaningfully alter the effects of race. However, when we controlled for infection rates in the no-vaccine scenario, mobility-based exposure had a negative effect on infection rates under vaccination $(\beta=-0.10, p<.001)$. This would appear to be because vaccination especially benefited those who were more at risk from either baseline or dynamic exposure. This would all indicate that mobility-based exposure had a moderate effect on continued infections, though it played a much smaller role relative to vaccination in determining infection trends. As a final test of this interpretation, we ran a model using only percentage vaccinated and mobility-based exposure to explain infection rates, and found that the effect of the former was four times the size of the effect of the latter $(\beta=-.78$ vs. $\beta=.21$, both $p$-values $<$ $.001)$.

If mobility-based exposure and vaccination are each relevant to the evolution of infections, the question remains how often these two factors coincide, making certain communities doubly vulnerable. We find that mobility-based exposure correlated moderately 
with the proportion of Black and Latinx residents (\% Black: $r=0.23, p<.01 ; \%$ Latinx: $\mathrm{B}=$ $0.23, p<.01)$ and was slightly negatively associated with vaccination rates $(r=-0.28, p<.01)$. Thus, although high levels of mobility-based exposure and vaccination do not always coincide, the communities where they do are at highest risk.

\section{Robustness Tests and Implications}

In order to probe the robustness of the simulation, we tested higher and lower levels of persuasion, as well as no persuasion; two lower levels of vaccine efficacy; and two longer timelines for vaccination roll-out. We re-ran the models with all possible combinations, making for 36 sets of results $(4 \times 3 \times 3)$. These alterations had the expected effects on global patterns, either extending or compressing vaccination time, or increasing or decreasing total infections. The disparities in infection rates and herd immunity were also present across models. We conducted a meta-analysis of the disparities in infection rates and the attainment of herd immunity, entering the levels of persuasion, vaccine efficacy, and distribution time into regressions predicting specific outcomes and parameters: the effects of \% Black and \% Latinx on infection rates, both with and without controlling for infection rates under the no-vaccine scenario; the difference in the proportion of predominantly White and high Black-Latinx communities that reached herd immunity; the difference between predominantly White and high Black-Latinx populations in the average date on which herd immunity was reached.

As illustrated in Figure 4, the level of persuasion had the strongest effect, markedly lowering all measures of disparity (all $p$-values $<.001$ ). Greater vaccine efficacy also lowered the association between percentage Black and Latinx population and infection rates, both in general and owing uniquely to the introduction of vaccination itself (i.e., relative to the no- 
vaccine scenario). Vaccine efficacy had little effect on disparities in reaching herd immunity, however. This was likely because less effective vaccines will extend the timeline to herd immunity for everyone, but the burden of allowing infections to persist will fall heaviest on those communities experiencing the most exposure. Last, a quicker rollout rate led to greater disparities when controlling for infections in the no-vaccination scenario and differences in the average date of reaching herd immunity. This is likely because high Black-Latinx communities reach the vaccination bottleneck sooner and thus fall behind their predominantly White counterparts at a faster rate. It is important to note, however, that the absolute outcomes were better for everyone under this scenario. Last, a faster rollout led to lower disparities in the raw infection rate for the Latinx population, but this appeared to attributable to the higher starting infection rate and mobility-based exposure in these communities, making a quick rollout especially valuable.

As we describe these differences across simulations, we must take into account their practical implications. The strength of persuasion is the most important component in the models, and it cuts both ways. If we remove persuasion entirely, $97 \%$ of predominantly White communities reach herd immunity in the 180-day simulation, with an average of 121 days, whereas no high Black-Latinx communities do. However, its power to eliminate disparities seems limited. When we increased the rate of persuasion by $50 \%$ from the baseline model, the average high Black-Latinx community saw herd immunity only 9 days earlier, while predominantly White communities saw an even smaller improvement of 3 days. This closed the gap between the two by only $14 \%$. This indicates that even if individuals uncertain about getting vaccinated are convinced to do so more quickly, the proportion of people committed to being 
vaccinated at the outset and, conversely, the proportion committed to not being vaccinated, are far more consequential in determining the timeline of reaching herd immunity.

\section{Discussion}

The simulation found that the introduction of vaccinations helped all communities. Disparities, however, between predominantly White communities and communities of color emerged early on and worsened as the simulations proceeded, following each of our four research questions. First, communities quickly reached a bottleneck in vaccination, at which point further vaccination relied entirely on continued persuasion. Because communities with more Black and Latinx residents had fewer people who are initially willing to be vaccinated, they reached this bottleneck weeks before predominantly White communities. Second, the disparities in vaccination rates set the stage for inequities in infection rates. Communities of color experienced average rates of infection 3 times as high as predominantly White communities and reached herd immunity on average a month-and-a-half later. Third, we found that persuasion is crucial to closing the infection gaps between communities of different racial backgrounds. Unfortunately, however, increasing the power of persuasion had limited additional effect because of the large number of people saying they would definitely not get vaccinated in communities of color. Fourth, mobility-based exposure had only a moderate impact during vaccination, meaning that lower adoption of vaccines in some communities did not heavily undermine herd immunity in surrounding areas. Overall, these results illuminate the nuanced emergence and persistence of inequities we might expect to observe as vaccination continues.

Going through the research questions in more detail, we turn first to the bottleneck in vaccination, which raises two points worth elaborating. From a logistical perspective, the 
assumptions of our model were such that persuasion could not keep pace with vaccine supply, creating implications for proper management of distribution. Meanwhile, from a social perspective, the earlier bottleneck in communities with more Black and Latinx residents meant that they had fewer people vaccinated at this point. Because the persuasion rate is dependent on the proportion of community members who have been vaccinated, these communities fell further and further behind in vaccination in the following weeks. Thus, for reasons both reasons of supply management and long-term advancement of the rollout, the bottleneck is a key moment in the evolution of the model and policymakers and practitioners should be attuned to any signals that this point is arriving and to ramp up community messaging accordingly.

Because of their lower levels of vaccination, communities of color were faced with a greater and more persistent threat of the virus than predominantly White communities. It is important to note the full meaning of this statement. All communities saw heavily diminished infection rates over the three-month simulation and eventual herd immunity by the end of six months. But it took communities of color longer to arrive at that point, meaning they experienced a substantially greater cumulative amount of infections (and, consequently, deaths) than predominantly White communities. Thus, this is neither a doomsday scenario, nor is it what any mayor or governor would want for their city or region.

With that in mind, persuasion will be most critical to planning and leadership moving forward. By varying the strength of persuasion across models we see just how important it is to outcomes in the vaccination rollout $(30,31,33)$. The starkest illustration of this is that when we removed persuasion from the model, no high Black-Latinx community reached herd immunity by the end of six months, compared with over $95 \%$ of predominantly White communities. More subtle, but equally telling, was the impact of increasing the rate of persuasion as it only 
marginally narrowed inequities. This is because our model reflected a leading strategy of focusing on those who are unsure about getting the vaccine. This strategy operates on the assumption that those who say they "definitely will not" get the vaccine cannot be convinced by any quantity of evidence $(10,34)$. Given the proportion of people who are currently saying they will never get vaccinated, especially in communities of color, this makes for a precarious situation.

If one follows the logic of taking those that say they will never get vaccinated at their current word for Boston, 1 in 5 Black and Latinx residents would never be vaccinated. This would pose a large stumbling block to achieving herd immunity for communities of color. Though we have estimated herd immunity as the first moment at which there are no infections in a community, there could still be pockets of low vaccination with concomitant gaps in the protective wall of community health (35). That said, vaccine hesitancy is not synonymous with vaccine denial, which questions efficacy and propagates potential harms from vaccines (36). With luck, some of those who are fully rejecting the idea of being vaccinated now are more hesitant than they are deniers, and they will be receptive to increased evidence of the vaccine's effectiveness and safety. Thus, the solution is not only to increase the rate at which people on the fence decide to be vaccinated; it is in convincing those steadfastly opposed to the vaccination to consider it.

Our fourth research question regarded the implications of lower vaccine adoption in some communities for the surrounding region. Namely, could lower adoption in one or more communities undermine the pursuit of herd immunity in surrounding communities? This would seem plausible given the known importance of cross-community mobility for transmission of the virus (21-26). We find here a mixed answer. Indeed, mobility-based exposure continued to 
predict infection rates, though with a strength far smaller than that of vaccination adoption. This is consistent with other work that has found that the importance of mobility has been largely supplanted by the impact of interventions intended to mitigate transmission of the virus, whether they be social distancing guidelines in the summer of 2020 or, in this case, vaccine rollouts (37). As such, the ability of a community with lower vaccine adoption to impact other communities around it appears to be limited.

There are a number of limitations to the model and its implications arising from assumptions we were forced to make. First, we did not account for any first-stage rollout to first responders, frontline workers, and the most at-risk, which is anticipated to reach $\sim 10-15 \%$ of the population. This would accelerate herd immunity by raising the baseline level of vaccination and kick-starting persuasion. Second, we assumed that vaccinated individuals cannot carry the virus, which has been a point of discussion with little evidence one way or the other. Last, our simplistic model of persuasion ignores the power of leadership, which is argued to be as critical in communities of color as seeing one's neighbors be vaccinated (38). All of these dynamics could alter the specific quantitative results we see here and the timeline to herd immunity. That said, given the variety of robustness tests that we have run, we are confident saying that in any of these scenarios there will be extensive inequities in infection rates and the time elapsed before achieving herd immunity between predominantly White and Asian communities and Black and Latinx communities.

\section{Materials and Methods}

The study centers on a SIR model that uses pre-determined transmission and recovery rates in conjunction with mobility between communities to estimate daily infection rates in each 
community. The models were run for October-December, 2020, and the transmission and recovery rates were based on actual infection records. Mobility was also derived from historical data for the same time period. The "communities" act as nodes in the mobility model and are defined as the 100 non-Boston cities in towns in the greater Boston region (following the Metropolitan Area Planning Council's definition) and the 28 ZIP codes within Boston. This decision was made based on the availability of more granular data for Boston as well as the large amount of between-ZIP code demographic diversity within the city, which is lower or absent in many of the surrounding municipalities.

\section{Data and Measures}

The models used four data sources: (1) population descriptors from the American Community Survey's 2014-2018 five-year estimates; (2) daily and weekly infection case counts, derived from infection records, for all towns in greater Boston and ZIP codes within Boston; (3) responses to two surveys including items on people's intentions regarding vaccination; (4) crosscommunity mobility records derived from cell phone records, generated by $\underline{\text { SafeGraph, a data }}$ company that aggregates anonymized location data from numerous applications in order to provide insights about physical places, via the Placekey Community. To enhance privacy,

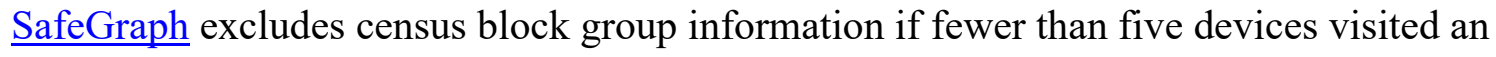
establishment in a month from a given census block group. The Boston Area Research Initiative's Geographical Infrastructure (39) was used to join data describing each municipality or ZIP code.

Census Indicators 
We drew population descriptors from the U.S. Census' American Community Survey's 20142018 estimates for all census block groups in Massachusetts. This level was selected as it is the largest census geography that nests cleanly within ZIP codes in Boston and within municipal boundaries. Community indicators included total population and ethnic composition (i.e., proportion Asian, proportion Black, proportion Latinx, proportion White). All measures were aggregated from census block groups to the municipal or ZIP code level using populationweighted means.

Infection Cases

The Commonwealth of Massachusetts' Department of Health released weekly counts of new infections for all municipalities, starting on April 14th, 2020. It also released daily counts for counties. From these two data sources we created daily town measures by: tabulating the weekly sum of infected cases in a county; calculating the percentage of a county's cases attributed to each town; estimating the daily infected cases per town as the same percentage of the daily count for the county. For Boston ZIP codes, we had case records tracked by the Boston Public Health Commission mapped to the ZIP code of residence. We tabulated these for daily counts.

\section{Surveys}

Three surveys of Massachusetts residents were conducted that included a question regarding intention to vaccinate and split these responses by race. The three surveys were conducted by the Center for Survey Research at University of Massachusetts Boston with the Boston Area Research Initiative, MassInc Polling on behalf of the Boston Museum of Science, and Suffolk University Polling and the Boston Globe. The first surveyed residents of Boston from September 
to November and the other two surveyed residents from throughout Massachusetts in November and December, respectively. Although the exact wording varied between them, all three surveys permitted respondents to say that they "definitely" or "definitely did not" plan to get the vaccine or that they were uncertain or undecided. The overall proportion of individuals falling in each of these three groups was consistent across the three surveys, as were the breakdowns by race (though the MassInc poll did not have enough Asian respondents to include cross-tabs for that group; see Supplementary Online Materials for full results).

We summed the cross-tabs for the vaccination intention question by race across the three surveys to calculate the weighted proportion of individuals indicating "as soon as possible," "never," and something in between for each of the four major racial categories--Asian, Black, Latinx, and White. We then estimated the proportion of residents in each of these three categories regarding the vaccine for each municipality and Boston ZIP code with the following equation:

$$
Y_{i, k}=\sum_{j} p_{i, j} * r_{j, k}
$$

where $Y_{i, k}$ is the proportion of residents in community $i$ with attitude $k$ toward the vaccine (e.g., getting it as soon as possible), $p_{i, j}$ is the proportion of residents in community $i$ of race $j$, and $r_{j, k}$ is the proportion of members of race $j$ giving $k$ as their response across the three surveys.

\section{Cellphone Generated Mobility Records}

We used SafeGraph's daily "Social Distancing" dataset to create the mobility network. The data are generated using a panel of GPS pings from anonymous mobile devices. Each device is attributed to an estimated home census block group (CBG) based on its most common nighttime location. It also tracks all stay points of these devices within other CBGs. The published data 
aggregate these pieces of information to generate a mobility matrix of the daily number of visits by the assumed residents of each CBG to each other CBG.

\section{Mobility-Driven SIR model with the Distribution of Vaccination}

Model

Our model was based on a traditional SIR (susceptible-infected-recovered) model that then incorporated two additional factors: mobility, to simulate the effect of contacts brought by the mobility between communities; and vaccination, to model the effect of the adoption of vaccination across communities. The full model consists of the following differential equations, which update daily:

$$
\begin{aligned}
& \partial_{t} j_{n}=\left(\alpha_{n} j_{n}+\gamma \sum_{m \neq n} \alpha_{n} w_{m n} j_{m} \frac{N_{m}}{N_{n}}+\gamma \sum_{n \neq m} \alpha_{m} w_{n m} j_{m}\right) s_{n}-\beta j_{n} \\
& \partial_{t} s_{n}=-\left(\alpha_{n} j_{n}+\gamma \sum_{m \neq n} \alpha_{n} w_{m n} j_{m} \frac{N_{m}}{N_{n}}+\gamma \sum_{n \neq m} \alpha_{m} w_{n m} j_{m}+\mu g\left(p_{n}\right)\right) s_{n} \\
& \partial_{t} r_{n}=\beta j_{n} \\
& \partial_{t} p_{n}=-g\left(p_{n}\right)+h u_{n} v_{n} \\
& \partial_{t} u_{n}=-h u_{n} v_{n} \\
& \partial_{t} v_{n}=g\left(p_{n}\right)
\end{aligned}
$$

where $N_{n}, j_{n}, s_{n}$, and $r_{n}$ represent the total population size, number of infected cases, susceptible individuals, and recovered cases, respectively, for a community at a given timepoint.

The equations, which model simultaneous change over time in infected, susceptible, and recovered individuals, rely on four main components. $\alpha_{n}$ is the growth rate of infections in a community (i.e., the expected number of new cases from existing cases). It is based on a global 
$\alpha_{0}$ in combination with a sigmoid function that accounts for fluctuation effects between

communities when $j_{n}$ is less than a threshold $\varepsilon$ i.e. $\alpha_{n}=\alpha_{0} \cdot \frac{\left(\frac{j_{n}}{\varepsilon}\right)^{4}}{1+\left(\frac{j_{n}}{\varepsilon}\right)^{4}}(40)$. The second component pertains to mobility, including two operands: $r_{I}=\gamma \sum_{m \neq n} \alpha_{n} w_{m n} j_{m} \frac{N_{m}}{N_{n}}$ calculates the possibility of an infected person in other communities $(m)$ visiting the community and infecting susceptible in community $n$; and $r_{R}=\gamma \sum_{n \neq m} \alpha_{m} w_{n m} j_{m}$ is the possibility of a susceptible person from the community visiting another community $(m)$ and becoming infected. $w_{m n}=F_{m n} / N_{m}$ where $F_{m n}$ indicates the total number of visits from community $m$ to community $n$, as captured by the cellphone generated mobility data. The average mobility rate gamma is defined as $\gamma=\frac{\sum_{m \in G} F_{m}}{\sum_{m \in G} N_{m}}$. The third component is the rate of recovery of infected individuals, represented by $\beta$, which is consistent across communities. All individuals who have been infected and recovered are permanently removed from the susceptible population.

The fourth component of the model is vaccination adoption, wherein $p_{n}$ is the proportion of people who will definitely receive the vaccine, $u_{n}$ is the proportion of people uncertain about getting the vaccine, and $v_{n}$ is the proportion of people who have already been vaccinated. $\mu$ reflects the effectiveness of the vaccine and $\mu \cdot v_{n}$ are treated as part of $r_{n}$ as they have been removed from the susceptible population. $h$ is the persuasion rate at which someone uncertain about getting the vaccine will be persuaded to do so, whose strength is contingent on the proportion of residents in the community who have already been vaccinated (i.e., $\left.h u_{n} v_{n}\right)$. We assume that $h$ is consistent across communities. Only those who were uncertain about the vaccine could be persuaded, not those who stated they would never get the vaccine. Actual vaccination is represented by the function $g\left(p_{n}\right)$, of the form: 


$$
g\left(p_{n}\right)=\left\{\begin{array}{cc}
c & p_{n} \geq c \\
p_{n} & p_{n}<c
\end{array}\right.
$$

in which $c$ is the maximum capacity of the vaccination rollout for a day.

\section{Fixed Parameters}

Multiple parameters were established in advance of estimating the final model. $\alpha$ and $\beta$, the transmission and recovery rate, were estimated by running the simulation without vaccination on historical mobility and infection data for September $30^{\text {th }}$ through December $22^{\text {nd }}$. Grid search identified a local optimum for $\alpha=0.096$ and $\beta=0.072$, which translate to the more familiar $R_{0}=\alpha / \beta=1.33 . \varepsilon$ was calculated as $\varepsilon=\frac{M}{\sum_{m \in G} N_{m}}=3.826 \times 10^{-5}$, where $M$ is the number of communities. $\mu$, or the vaccine effectiveness, was set to 0.95 , per the Pfizer and Moderna trial results. The rate of vaccine rollout was initially set to a 12-week (approx. 3-month) rollout period, meaning $c=1 /(7 * 12)=.0119$, or $1.19 \%$ of the population could be expect to be vaccinated daily.

In addition, we had to extend the simulation for three additional months for determining herd immunity (i.e., $<1$ infection; the model permits fractions of infections), because only a third of communities had reached it by this definition at the end of the initial simulation. Two extreme scenarios are designed to impute the mobility data after Jan 12, 2021 to ensure that the real mobility data lies between the two imputed mobility datasets. We assume a cumulative $5 \pm 0.5 \%$ increase or decrease for every two weeks to the real mobility data from Dec 29, 2020, to Jan 11, 2021.

For $h$, we assume that the rate at which individuals uncertain about taking the vaccine are persuaded to do so is dependent on the number of people in their community who have received 
the vaccine. The number of people a person knows in their neighborhood and the number of people they need to know who have been vaccinated to be persuaded both vary by individual. In terms of likelihood to be persuaded, we use an additional item from the Mass Inc-Museum of Science survey regarding when people would be likely to get vaccinated. We note two groups: those who would like to see a few people get the vaccine before they do, and those who would like to see many other people get it. We use the cross-tabs from this question with the initial vaccination intention question to distribute them within the sample (see Supplementary Online Materials), and differentiate between these functionally in the model based on how many members of their neighborhood need to be vaccinated for them to be persuaded. Numerous neighborhood surveys have found that people say they are friends with or personally know very few of those living in their neighborhood (e.g., 5 people on one's street, less than 10 friends in the neighborhood, 40). Based on these numbers, we estimate that the average individual knows approximately $1 \%$ of the residents of his or her neighborhood well enough to know and relate to their vaccination experiences. We further estimate that if about $25 \%$ of these people (i.e., $0.25 \%$ of the population) were vaccinated, the average person would know at least "a few" people who had been vaccinated. Approximately $37 \%$ of people who were uncertain about vaccination said they would do so once "a few people they knew" were, the remainder when "many people" were. From this, we estimate that when $25 \%$ of the residents of a neighborhood are vaccinated, $18.5 \%$ of those who started out as uncertain will have been persuaded (that is, half of $37 \%$, as only the average person would have enough exposure at that time). Based on the same results, we believe that the asymptote for persuasion is at $90 \%$. We solved for these established points in a sigmoid function and found $h=.026$. All fixed parameters, their meaning, source, and value in the baseline model are reported in Table 1. 
Robustness Tests

We ran iterations of the model to test for robustness, varying three elements: persuasion, vaccine efficacy, and timeline of vaccine roll-out. We tested persuasion as $50 \%$ stronger $(h=.039)$ and $50 \%$ weaker $(h=.013)$, as well as the absence of persuasion altogether $(h=0)$. We tested vaccine efficacy at the lower points of $85 \%$ and $75 \%$. We tested the timelines for vaccination roll-out at four and six months ( $c=.0089$ and .0056 , respectively). We re-ran the simulation with all possible combinations, making for 36 sets of results $(4 \times 3 \times 3)$. All parameters are reported in Table 1. 


\section{References and Notes}

1. R. M. Anderson, R. M. May, Vaccination and herd immunity to infectious diseases. Nature 318, 323-329 (1985).

2. H. Rashid, G. Khandaker, R. Booy, Vaccination and herd immunity: what more do we know? Current Opinion in Infectious Diseases 25, 243-249 (2012).

3. S. E. A. Network, "COVID-19 Survey Summary: December 18, 2020," (Washington, D.C., 2020).

4. K. Pogue et al., Influences on attitudes regarding potential COVID-19 vaccination in the United States. Vaccines 8, 1-14 (2020).

5. S. Taylor et al., A proactive approach for managing COVID-19: the importance of understanding the motivational roots of vaccination hesitancy for SARS-CoV2. Frontiers in Psychology 11, 575950 (2020).

6. A. Domnich et al., Attitudes and beliefs on influenza vaccination during the COVID-19 pandemic: results from a representative Italian survey. Vaccines 8, 1-20 (2020).

7. J. Wang et al., Acceptance of COVID-19 vaccination during the COVID-19 pandemic in China. Vaccines 8, (2020).

8. S. M. Sherman et al., COVID-19 vaccination intention in the UK: results from the COVID-19 vaccination acceptability study (CoVAccS), a nationally representative crosssectional survey. Human vaccines \& immunotherapeutics, 1-10 (2020).

9. D. Freeman et al., COVID-19 vaccine hesitancy in the UK: the Oxford Coronoavirus explanations, attitudes, and narratives survey (OCEANS) II. (2020).

10. S. Neumann-Bohme et al., Once we have it, will we use it? A European survey on willingness to be vaccinated against COVID-19. European Journal of Health Economics 21, 977-982 (2020).

11. L. Hamel, A. Krirzinger, C. Munana, M. Brodie, "KFF COVID-19 Vaccine Monitor: December 2020," (Kaiser Family Foundation, Washington, D.C., 2020).

12. P. Hobson-West, Understanding vaccination resistance: moving beyond risk. Health, Risk \& Society 5, 273-283 (2003).

13. P. H. Streefland, Public doubts about vaccination safety and resistance against vaccination. Health Policy 55, 159-172 (2001).

14. S. Quinn, A. Jamison, D. Musa, K. Hilyard, V. Freimuth, Exploring the continuum of vaccine hesitancy between African American and White adults: results of a qualitative study. PLoS Currents 29, ecurrents.outbreaks.3e4a5ea39d8620494e8620492a8620492c8620874a8620493c862420 1 (2016).

15. P. Schmid, D. Rauber, C. Betsch, G. Lidolt, M.-L. Denker, Barriers of influenza vaccination intention and behavior - a systematic review of influenz vaccine hesitancy, 2005-2016. PLoS One 12, e0170550 (2017).

16. D. Hawkins, Differential occupational risk for COVID-19 and other infection exposure according to race and ethnicity. American Journal of Inudstrial Medicine, 1-4 (2020).

17. M. A. Garcia, P. A. Homan, C. Garcia, T. H. Brown, The color of COVID-19: structural racism and the disproportionate impact of the pandemic on older Blank and Latinx adults. Journals of Gerontoloy B: Psychology \& Social Sciences, 1-6 (2020).

18. L. Kirksey, D. L. Tuker, J. Taylor, Eddie, K. T. White Solaru, J. Modlin, Charles S., Pandemic superimposed on epidemic: COVID-19 disparities in Black Americans. Journal of the National Medical Association, 1-5 (2020). 
19. M. R. Lamb, S. Kandula, J. Shaman, Differential COVID-19 case positivity in New York City neighborhoods: socioeconomic factors and mobility. Influenza and Other Respiratory Viruses, 1-9 (2020).

20. M. S. Bryan et al., COVID-19 mortality and neighborhood charcteristics in Chicago. Annals of Epidemiology, (2020).

21. S. Chang et al., Mobility network models of COVID-19 explain inequities and inform reopening. Nature, 1-26 (2020).

22. H. S. Badr et al., Association between mobility patterns and COVID-19 transmission in the USA: a mathematical modelling study. Lancet Infectious Diseases 20, 1247-1254 (2020).

23. M. Chinazzi et al., The effect of travel resitraictions on the spread of the 2019 novel oronavirus (COVID-19) outbreak. Science 368, 395-400 (2020).

24. J. Zhang et al., Changes in contact patterns shape the dynamics of the COVID-19 outbreak in China. Science, (2020).

25. J. Zhang et al., Evolving epidemiology and transmission dynamics of coronavirus disease 2019 outside Hubei province, China: a descriptive and modelling study. Lancet Infectious Diseases, (2020).

26. M. U. G. Kraemer et al., The effect of human mobility and control measures on the COVID-19 epidemic in China. Science 368, $493-497$ (2020).

27. E. Mahase, Covid-19: Logistical problems frustrate GPs ready to deliver vaccine in England. BMJ: British Medical Journal (Online), 371, 2020.

28. M. Chinazzi et al. (Network Science Institute, Northeastern University, Boston, MA, 2020).

29. C. M. Angst, R. Agarwal, Adoption of electronic health records in the presence of privacy concerns: the elaboration likeilhood model and individual persuasion. MIS Quarterly 33, 339-370 (2009).

30. S. Battacharyya, C. T. Bauch, "Wait and see" vaccinating behaviour during a pandemic: a game theoretic analysis. Vaccine 29, 5519-5525 (2011).

31. F. Fu, N. A. Christakis, J. H. Fowler, Dueling biological and social contagions. Scientific Reports 7, 43634 (2017).

32. S. Le Chang, M. Piraveenan, M. Prokopenko, The effects of imitation dynamics on vaccination behaviours in SIR-network model. International Journal of Environmental Research and Public Health 16, 2477-2507 (2019).

33. F. Fu, D. I. Rosenbloom, L. Wang, M. A. Nowak, Imitation dynamics of vaccination behaviour on social networks. Proceedings of the Royal Society B-Biological Sciences 278, 42-49 (2011).

34. P. Schmid, N. E. Macdonald, K. Habersat, R. Butler, Commentary to: How to respond to vocal vaccine deniers in public. Vaccine 36, 196-198 (2018).

35. K. Estep, P. Greenberg, Opting out: individualism and vaccine refusal in pockets of socioeconomic homogeneity. American Sociological Review 85, 957-991 (2020).

36. E. Dube et al., Vaccine hesitancy: an overview. Human vaccines \& immunotherapeutics 9, 1763-1773 (2013).

37. O. Gatalo, K. Tseng, A. Hamilton, G. Lin, E. Klein, Associations between phone mobility daya and COVID-19 cases. Lancet Infectious Diseases, (2020).

38. R. J. Gallagher, L. Doroshenko, S. Shugars, D. Lazer, B. Foucault Welles. (arXiv, 2020). 
39. A. Ristea, S Sheini, D. T. O'Brien, Geographical Infrastructure for the City of Boston v. 2020, https://doi.org/10.7910/DVN/W0V6FX, Harvard Dataverse, V1 (2020).

40. D. Brockmann, D. Helbing, The hidden geometry of complex, network-driven contagion phenomena. Science 342, 1337-1342 (2013).

41. R. J. Sampson, Great American City: Chicago and the Enduring Neighborhood Effect., University of Chicago Press, Chicago (2012).

Acknowledgments: We thank our colleagues at the City of Boston and Boston Public Health Commission for feedback on the concept and early analyses and SafeGraph for the provision of mobility data.

Funding: National Science Foundation RAPID grant from the Geography and Spatial Sciences program BCS-2032384 (DTO, LH, QW, AR, RS)

\section{Author contributions:}

Conceptualization: YW, AR, LH, JG, QW, DTO

Data Curation: AR, MA, SG, LH, HG, NK

Formal Analysis: YW, AR

Methodology: YW, AR, JG, QW, DTO

Investigation: AR, LH, RS, DD, QW, DTO

Visualization: AR

Funding acquisition: AR, LH, RS, QW, DTO

Project administration: AR, LH, AR, RS, DTO

Writing - original draft: DTO

Writing - review \& editing: AR, LH, AR, RS, DD, JG, QW, DTO

Competing interests: Authors declare that they have no competing interests.

Data and materials availability: The population descriptors from the U.S. Census' American Community Survey's 2014-2018 estimates were used from the processed and curated open database of BARI. According to the mobility data agreement, SafeGraph is providing free access to various datasets only to researchers, non-profits, and governments around the world which are working directly in the response to COVID-19, reason why this dataset is not open for reproducibility. The COVID-19 infection counts are openly available per week and day from the Massachusetts governmental website at town and county level. The COVID-19 infection counts for the City of Boston were processed from BPHC based on a shared data agreement, and we do not have the rights to publicly share the data. The vaccination information was derived from the Living in Boston survey, which was designed and implemented by the authors of this manuscript. The vaccination data is available upon request. Modeling code will be posted through GitHub upon publication of the paper.

Human Participant Statements: We confirm that the survey "Living in Boston During COVID-19 Survey" conducted by the authors of this manuscript has IRB approval from the University of Massachusetts Boston and Northeastern University. All methods were 
carried out in accordance with relevant guidelines and regulations. Informed consent was obtained when all subjects were informed that all responses are confidential. No information will be presented or published in any way that permits identification of individuals.

\section{Supplementary Materials}

Figs. S1 to S3

Tables S1 to S6 
A

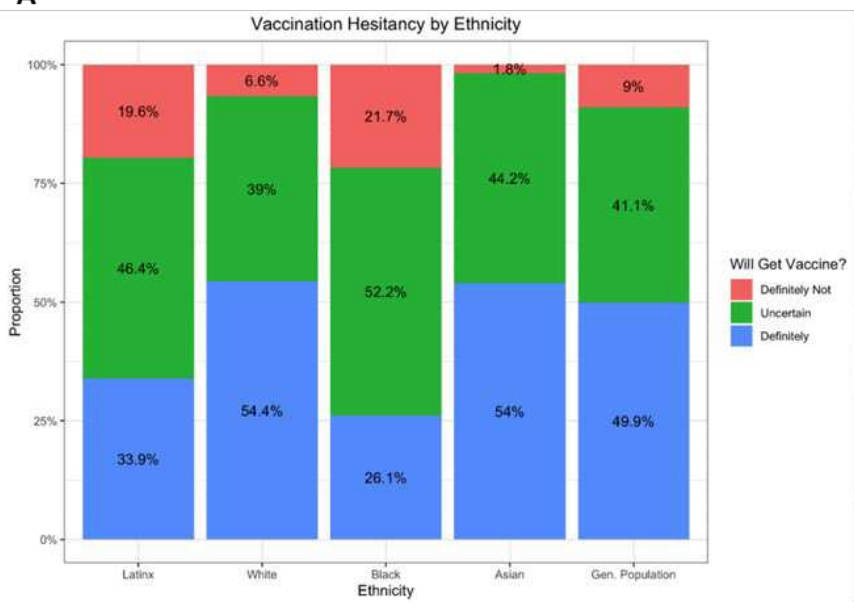

B

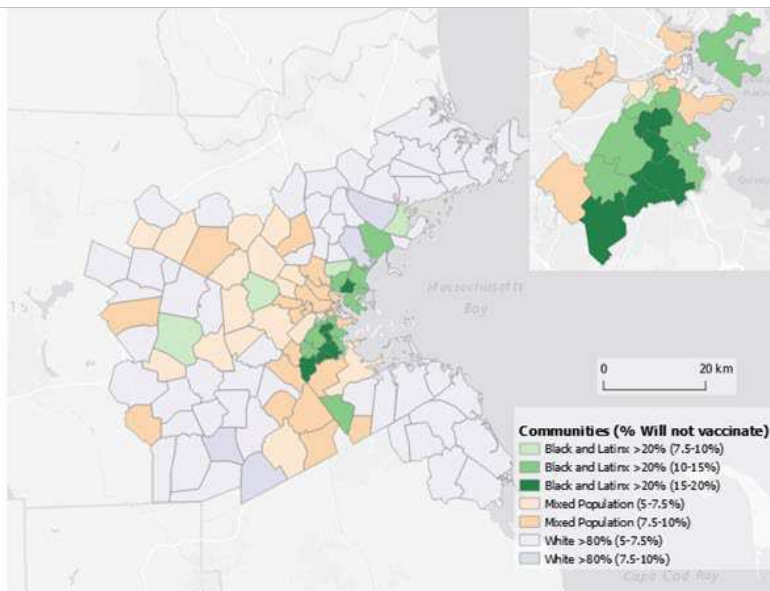

Fig. 1. Representation of variations in vaccine intentions. (A) Individuals vary in their intentions to receive the vaccine by ethnicity. When combined with $(\mathbf{B})$ the categorization of communities by predominantly White $(>80 \%)$, high Black-Latinx $(>20 \%)$, or other, these disparities translate into geographic differences in the proportion who definitely will not vaccinate. 
A

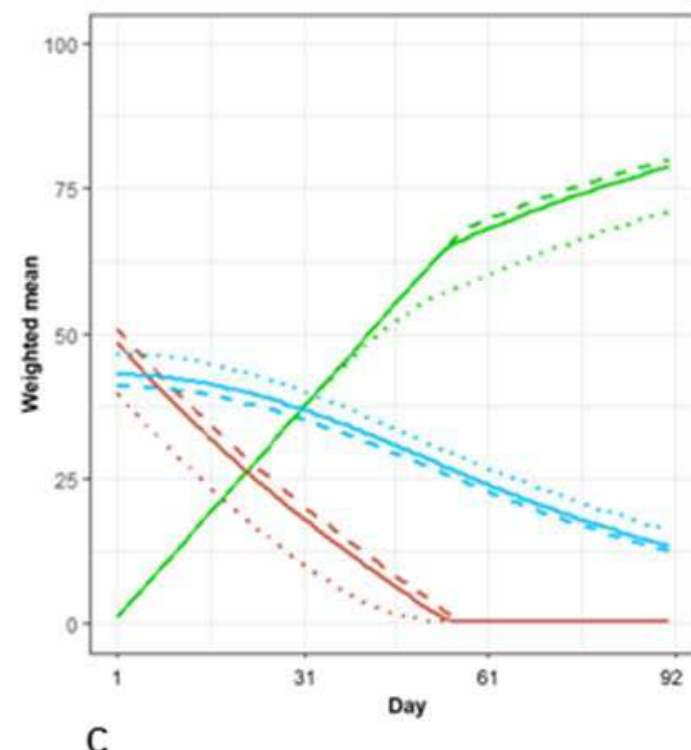

B

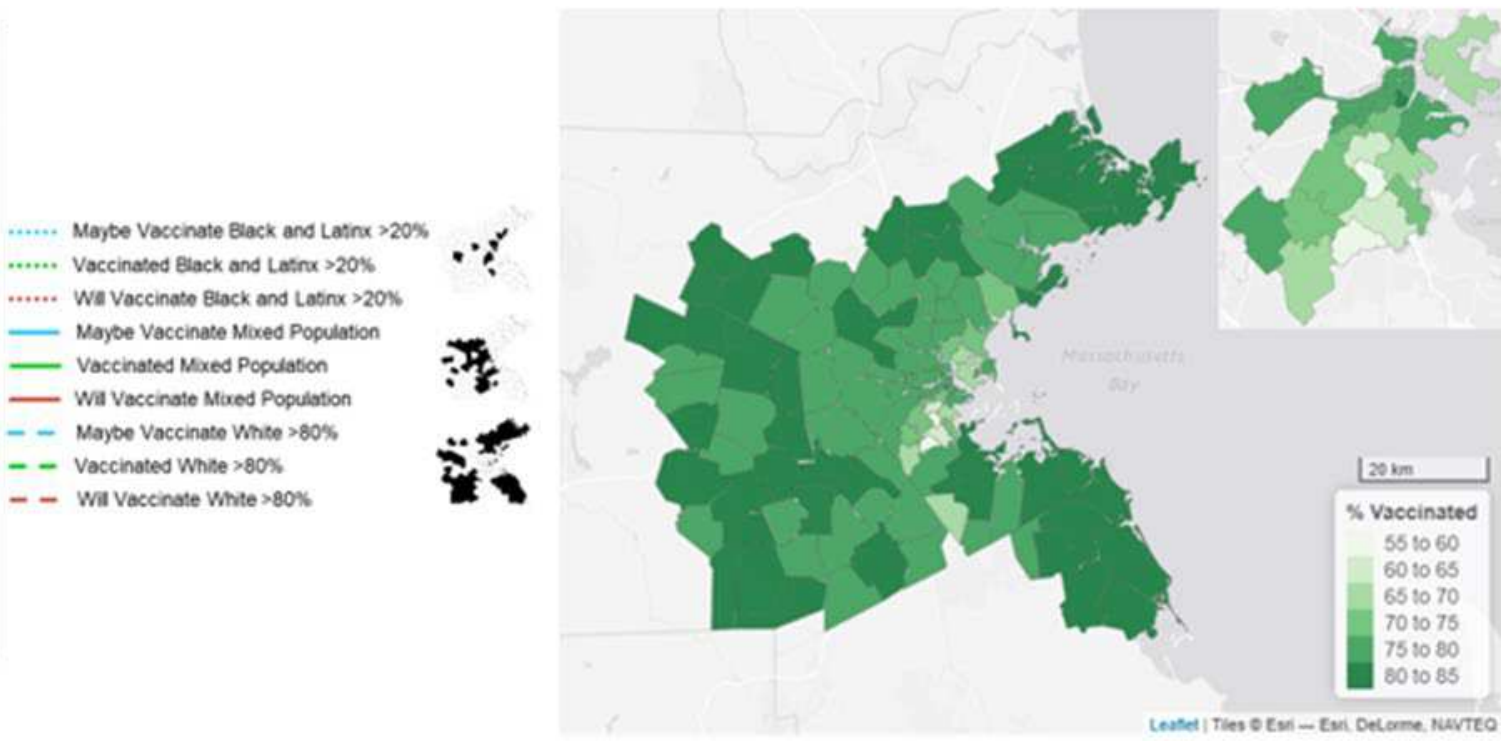

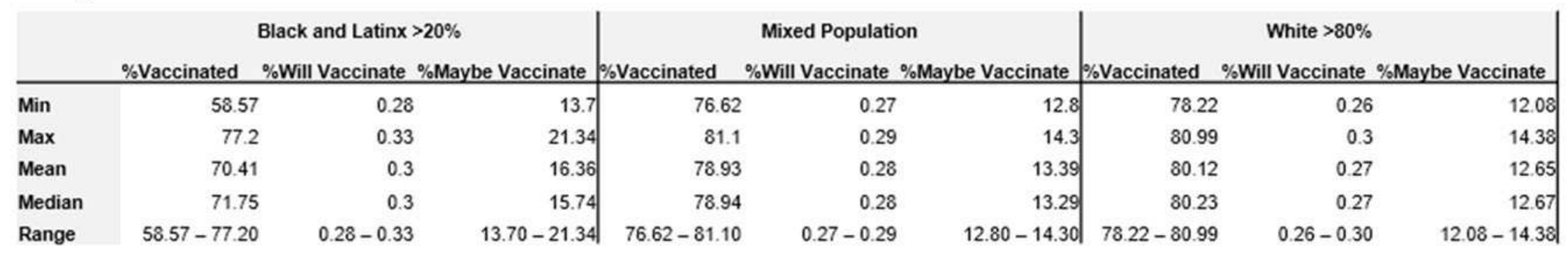

Fig. 2. Vaccination rates varied across communities throughout the simulation. (A) Growth curves of the percentage of residents intending to vaccinate, will maybe vaccinate, and have been vaccinated across the three-month simulation, broken out by communities that are predominantly White, high Black-Latinx, and other. These different curves resulted in disparities across communities in (B) the total percentage of those vaccinated at the end of the simulation. (C) shows the disparities at the end of the modeling process. 


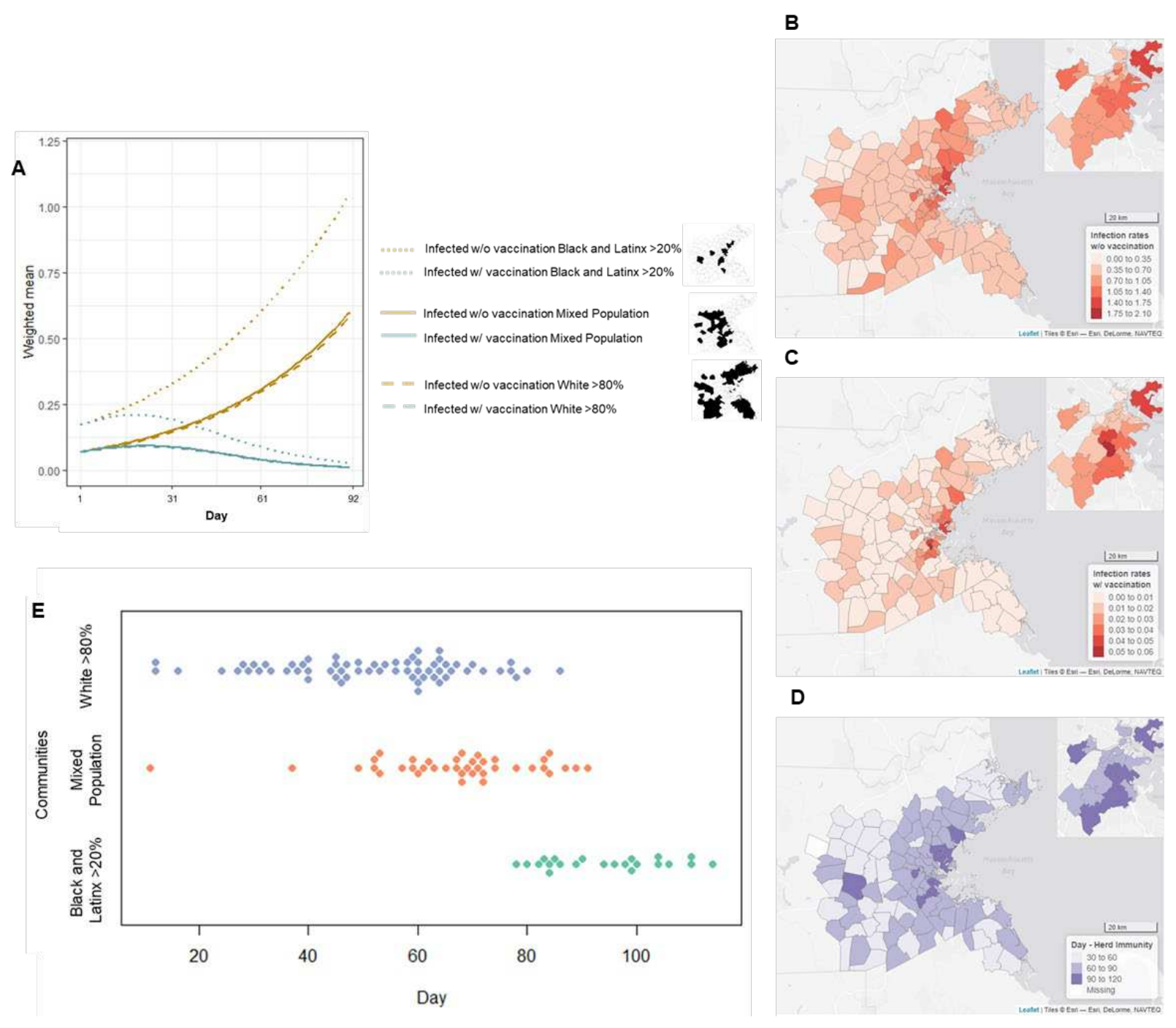

Fig. 3. Vaccination rates varied across communities throughout the simulation. (A) Growth curves of the percentage of residents intending to vaccinate, will maybe vaccinate, and have been vaccinated across the three-month simulation, broken out by communities that are predominantly White, high Black-Latinx, and other. These different curves resulted in disparities across communities in (B) the total percentage of those vaccinated at the end of the simulation. (C) shows the disparities at the end of the modeling process. (D) shows the day when heard immunity is reached per communities on the map, while (E) shows a graphic representation of when communities reach herd immunity. 


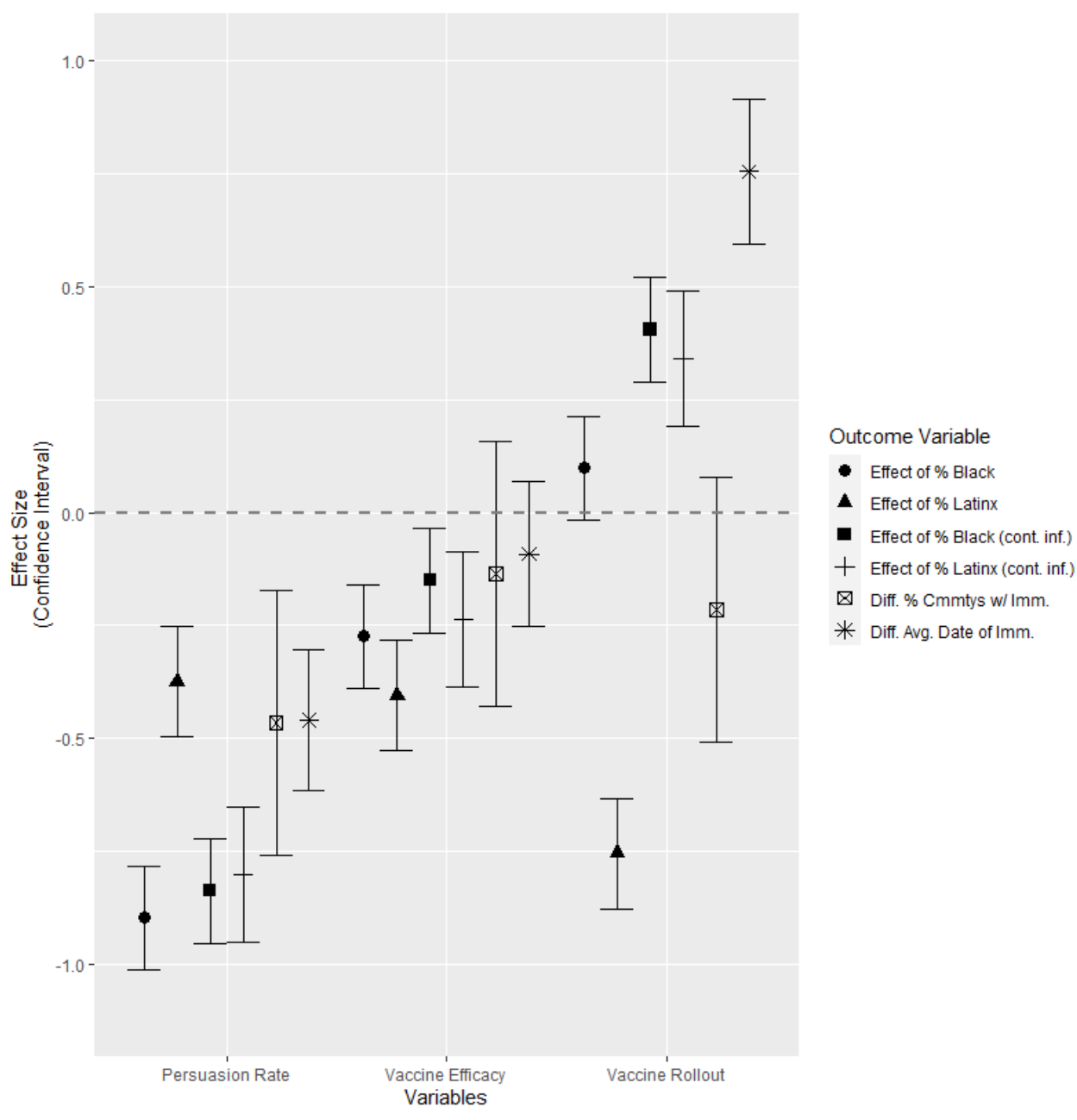

Fig. 4. Disparity across simulations. Parameter estimates (unstandardized betas, standard errors, and standardized betas) from regression equations meta-analyzing the indicators of disparity from across simulations with different levels of persuasion, vaccine efficacy, and rollout rate. 
Table 1. Fixed values and sources for parameters in the baseline simulation model and robustness checks.

\begin{tabular}{|c|c|c|c|}
\hline Parameter & Meaning & $\begin{array}{c}\text { Value } \\
\text { (Robustness } \\
\text { Checks) }\end{array}$ & Source \\
\hline$\alpha^{\mathrm{a}}$ & Transmission rate & .096 & $\begin{array}{l}\text { Modeled on historical infections, } \\
\text { mobility }(9 / 30-12 / 22)\end{array}$ \\
\hline$\beta^{\mathrm{a}}$ & Recovery rate & .072 & Modeled on historical infections \\
\hline$\mu$ & Vaccine effectiveness & $\begin{array}{c}0.95 \\
(0.75,0.85)\end{array}$ & $\begin{array}{l}\text { Pfizer and Moderna trial results } \\
(26,27)\end{array}$ \\
\hline$c$ & $\begin{array}{l}\text { Weekly rollout ( } \% \text { of } \\
\text { population) }\end{array}$ & $\begin{array}{c}.0119 \\
(0.0089 \\
0.0056)\end{array}$ & $\begin{array}{l}\text { Based on three-month (12-week) } \\
\text { rollout }\end{array}$ \\
\hline$h$ & Persuasion rate & $\begin{array}{c}.026 \\
(0,0.013 \\
0.039)\end{array}$ & $\begin{array}{l}\text { Sigmoid function based on } \\
\text { neighborhood surveys about } \\
\text { number of neighbors known (41) }\end{array}$ \\
\hline
\end{tabular}

a - The more familiar $R_{0}=\alpha / \beta=1.33$. 
Table 2. Parameter estimates from regression equations using demographic composition, mobility-based exposure, and expectations from the no-vaccine scenario to predict infection rates at the end of the vaccination simulation.

\begin{tabular}{|c|c|c|c|c|c|c|c|c|}
\hline & $\begin{array}{l}\text { Unstand. } \\
\text { Beta (S.E.) }\end{array}$ & $\boldsymbol{\beta}$ & $\begin{array}{l}\text { Unstand. } \\
\text { Beta (S.E.) }\end{array}$ & $\boldsymbol{\beta}$ & $\begin{array}{l}\text { Unstand. } \\
\text { Beta (S.E.) }\end{array}$ & $\beta$ & $\begin{array}{l}\text { Unstand. } \\
\text { Beta (S.E.) }\end{array}$ & $\beta$ \\
\hline $\begin{array}{l}\text { Exp. } \\
\text { Infections }{ }^{\mathrm{a}}\end{array}$ & - & - & $\begin{array}{c}0.02 * * * \\
(0.001)\end{array}$ & .53 & - & - & $\begin{array}{c}0.02 * * * \\
(0.001)\end{array}$ & .61 \\
\hline$\%$ Black & $\begin{array}{c}0.30 * * * \\
(0.03)\end{array}$ & .42 & $\begin{array}{c}0.26^{* * * *} \\
(0.01)\end{array}$ & .37 & $\begin{array}{c}0.26 * * * \\
(0.03)\end{array}$ & .36 & $\begin{array}{c}0.28 * * * \\
(0.01)\end{array}$ & .39 \\
\hline$\%$ Latinx & $\begin{array}{c}0.54 * * * \\
(0.04)\end{array}$ & .63 & $\begin{array}{c}0.26^{* * * *} \\
(0.02)\end{array}$ & .30 & $\begin{array}{c}0.50 * * * \\
(0.04)\end{array}$ & .58 & $\begin{array}{c}0.23 * * * \\
(0.02)\end{array}$ & .27 \\
\hline$\%$ Asian & $\begin{array}{l}-0.05 \\
(0.04)\end{array}$ & -.04 & $\begin{array}{c}-0.07 * * * \\
(0.02)\end{array}$ & -.06 & $\begin{array}{l}-0.10^{*} \\
(0.04)\end{array}$ & -.09 & $\begin{array}{l}-0.05^{*} \\
(0.02)\end{array}$ & -.04 \\
\hline $\begin{array}{l}\text { Mobility- } \\
\text { based } \\
\text { Exposure }^{\mathrm{b}}\end{array}$ & - & - & - & - & $\begin{array}{c}0.02 * * * \\
(0.004)\end{array}$ & .22 & $\begin{array}{c}-0.01 * * * \\
(0.002)\end{array}$ & -.10 \\
\hline
\end{tabular}

${ }^{*} \mathrm{p}<0.05 ;{ }^{* * *} \mathrm{p}<0.001$

Note: For 128 communities, defined as the municipalities of the greater Boston region and the ZIP codes within Boston. ${ }^{a}$ - Based on rates in the no-vaccine scenario. ${ }^{b}$ - Potential exposure to infection transmission via movement between communities, as derived from the model parameters. 


\section{Supplementary Materials for}

Title: Vaccination Intentions Generate Racial Disparities in the Societal Persistence of COVID-19

This file includes:

Figs. S1 to S3

Tables S1 to S7 
A

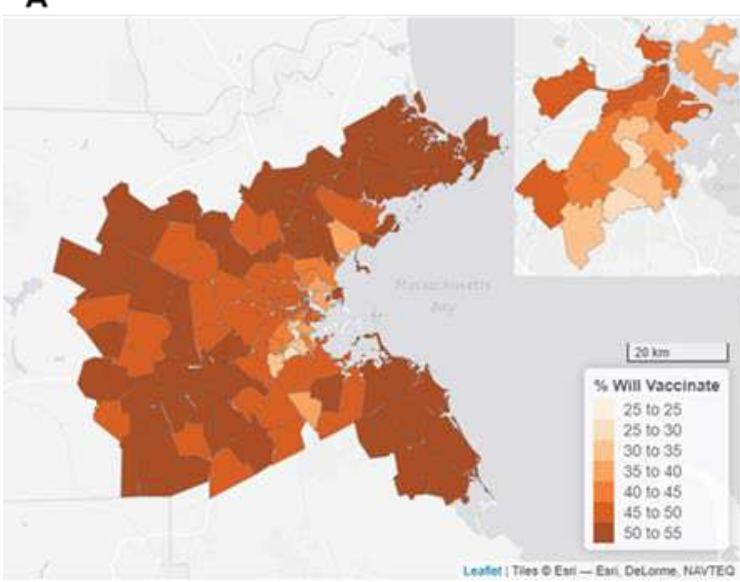

B

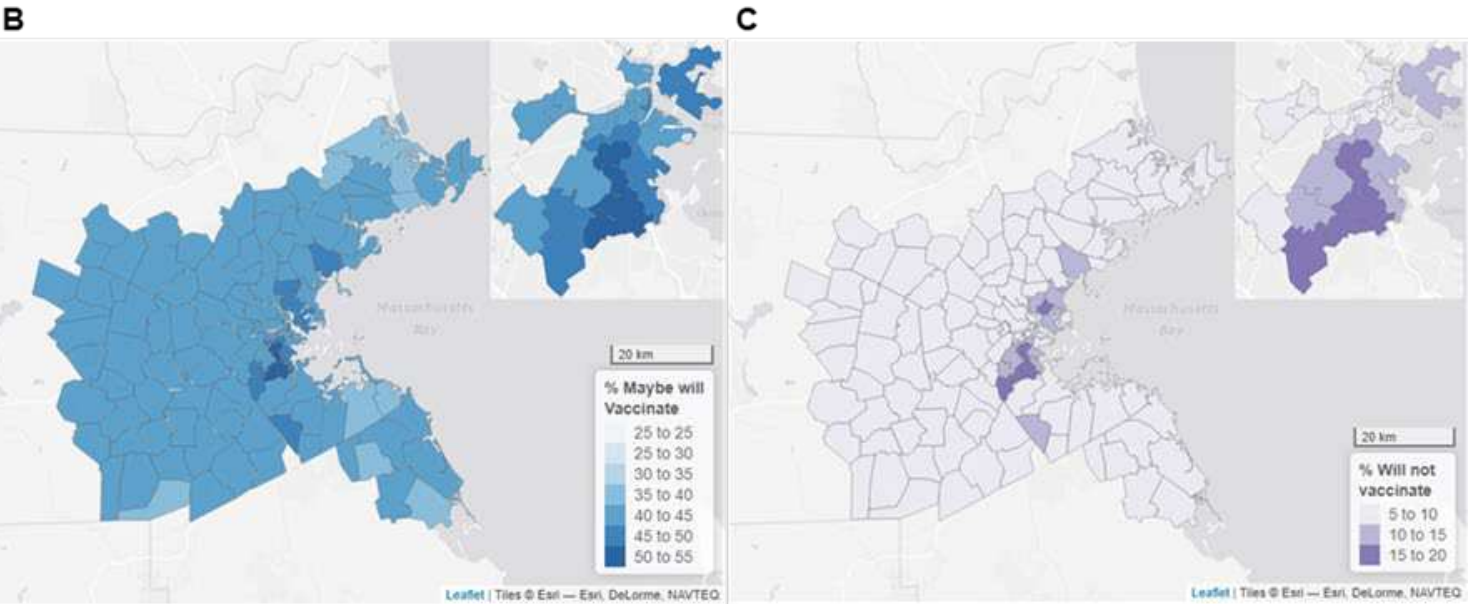

Fig. S1.

Representation of variations in vaccine intentions. Geographic differences in the proportion that (a) will definitely vaccinate, (b) maybe will vaccinate, and (c) definitely will not vaccinate. 
A
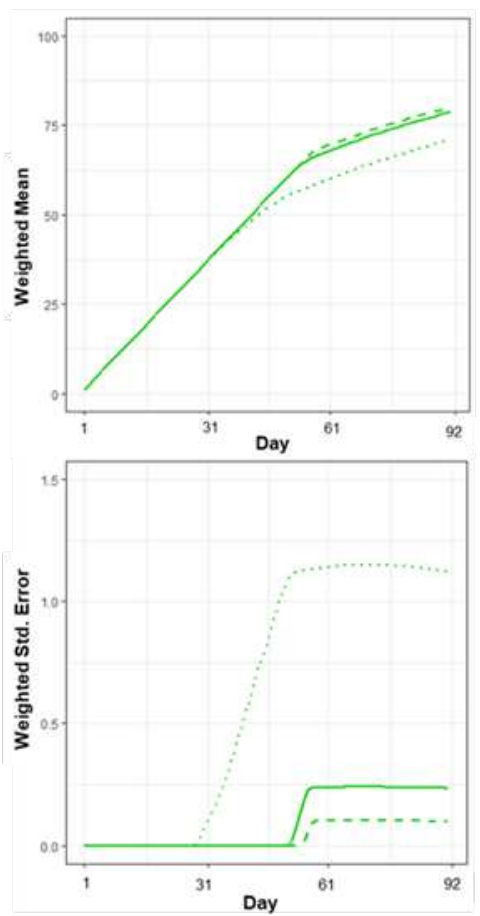

...... Vaccinated Black and Latinx $>20 \%$ ....... Will Vaccinate Black and Latin $>20 \%$ Maybe Vaccinate Black and Latinx $>20 \%$
B
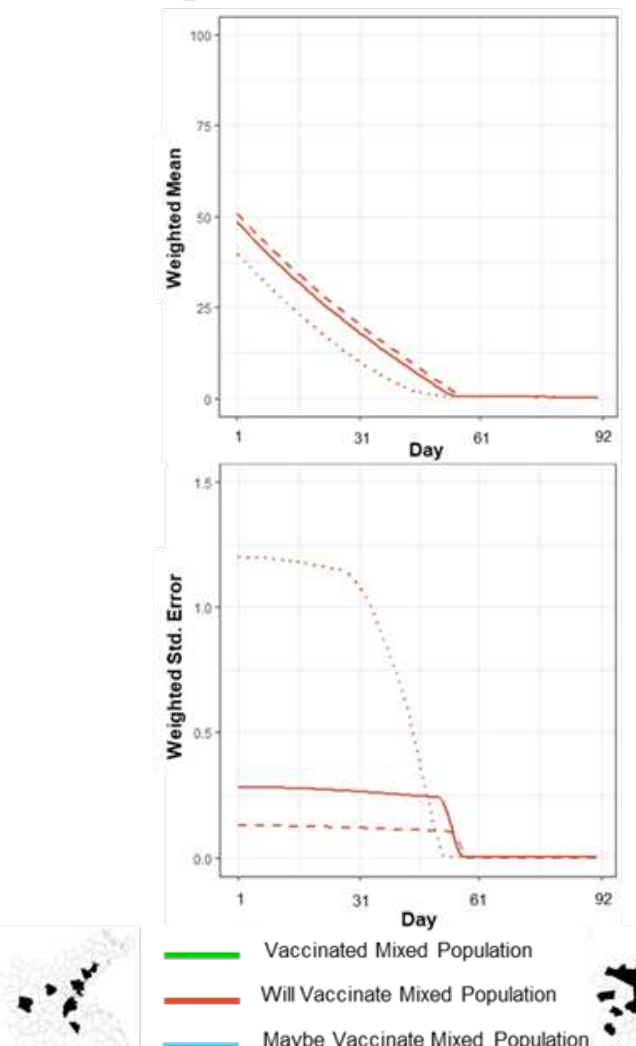

\section{C}
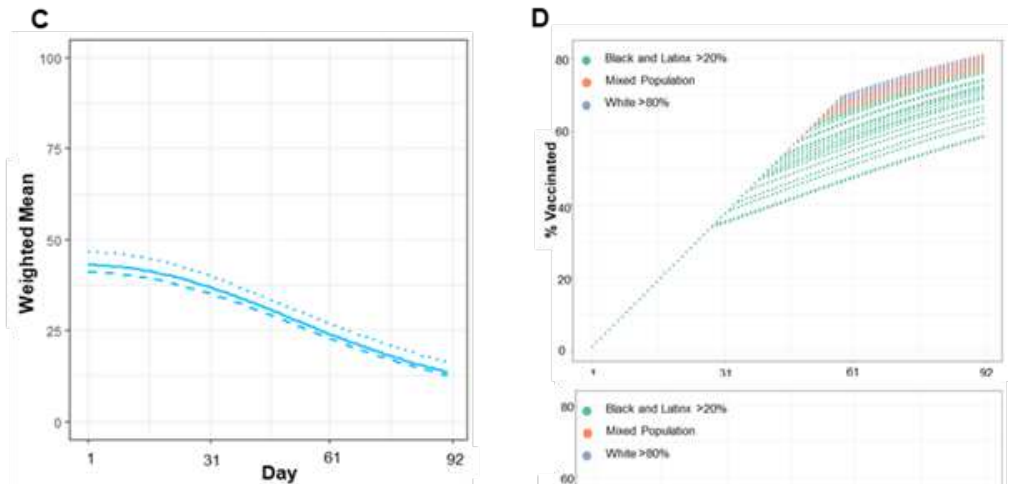

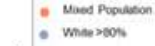
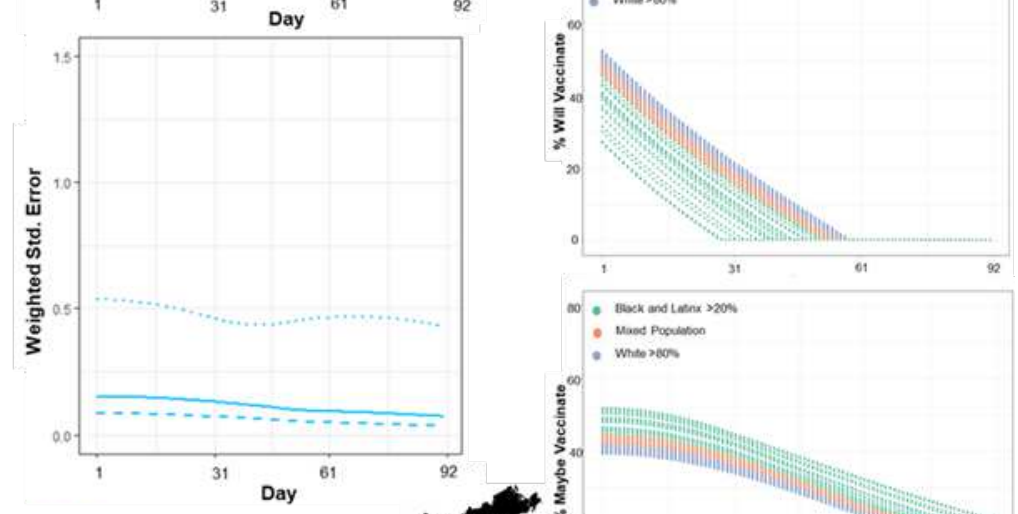

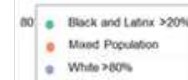

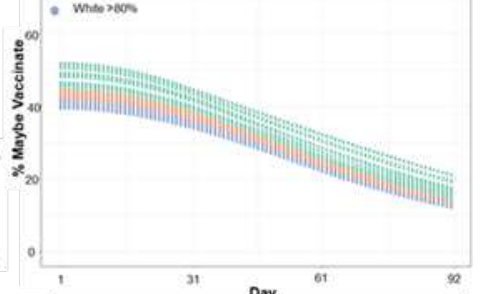

Fig. S2.

Disparities between communities of different ethnic composition across the simulation in (a) those vaccinated, (b) those will definitely vaccinate, and those who (c) maybe will vaccinate, including weighted mean across communities (top panel) and weighted standard error (bottom panel). (d) The same curves as in (a-c) for every individual community, categorized by racial composition. 
A
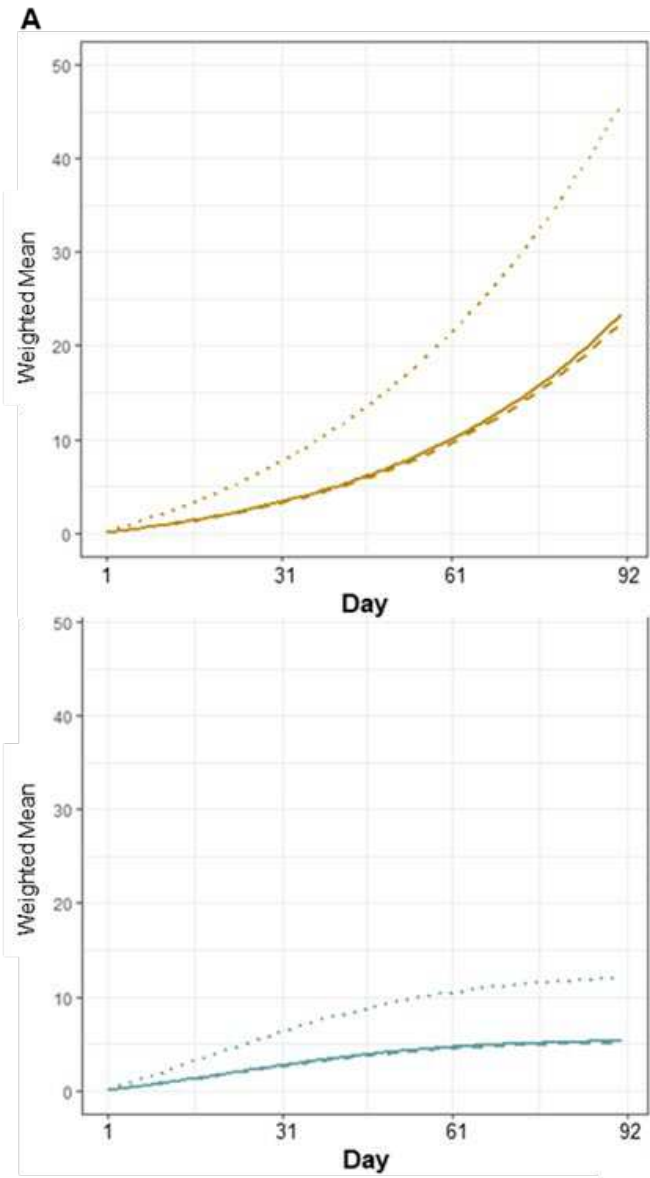

Infected w/o vaccination Black and Latinx $>20 \%$ Infected $w /$ vaccination Black and Latinx $>20 \%$
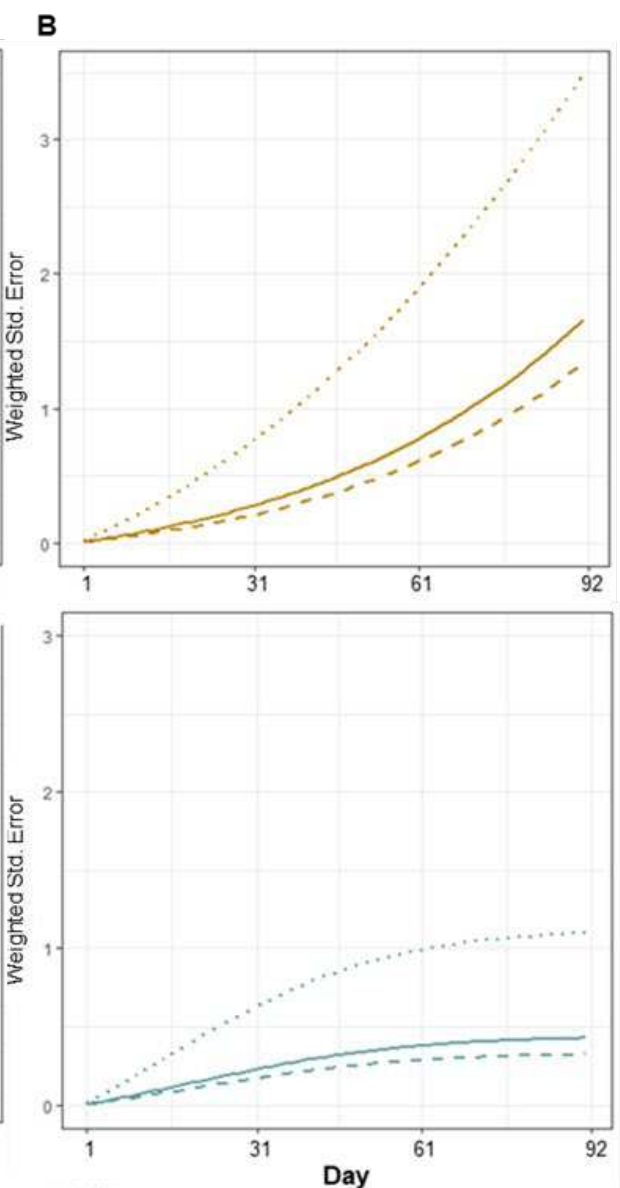

$\because$ c
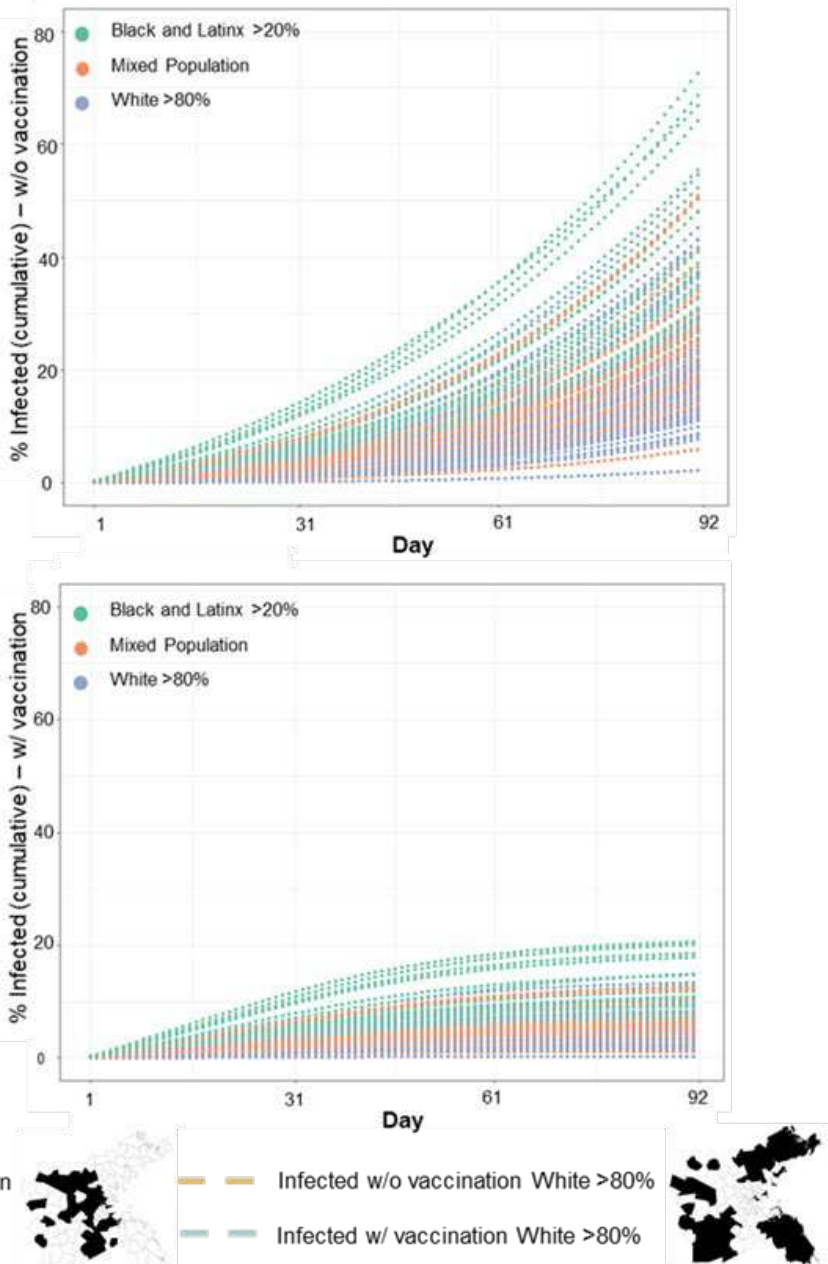

Fig. S3.

Community disparities shown for in the proportion of infected for the without vaccination (top panel) and with vaccination (bottom panel). (a) The weighted mean of infections by category of racial composition and (b) the weighted standard errors. (c) Cumulative values of proportion of infected residents, with one curve for every community, colored by category of racial composition. 


\section{Table S1.}

Responses by race to the question "Will you get vaccinated?" in the Center for Survey ResearchBoston Area Research Initiative survey.

\begin{tabular}{|l|c|c|c|c|c|}
\hline & Asian & Black & Latinx & White & Total \\
\hline Definitely & $44(.49)$ & $21(.25)$ & $24(.34)$ & $350(.56)$ & $\mathbf{4 3 9}(.51)$ \\
\hline Probably & $34(.38)$ & $26(.31)$ & $27(.39)$ & $207(.33)$ & $\mathbf{2 9 4}(.34)$ \\
\hline Probably Not & $9(.10)$ & $21(.25)$ & $11(.16)$ & $50(.08)$ & $\mathbf{9 1}(.11)$ \\
\hline Definitely Not & $2(.02)$ & $16(.19)$ & $8(.11)$ & $14(.02)$ & $\mathbf{4 0}(.05)$ \\
\hline Total & $\mathbf{8 9}$ & $\mathbf{8 4}$ & $\mathbf{7 0}$ & $\mathbf{6 2 1}$ & $\mathbf{8 6 4}$ \\
\hline
\end{tabular}




\section{Table S2.}

Responses by race to the question "When an FDA-approved vaccine for COVID is made available, how likely will you be to take it?" in the Mass Inc.-Museum of Science survey.

\begin{tabular}{|l|c|c|c|c|}
\hline & Black & Latinx & White & Total \\
\hline Very likely & $27(.33)$ & $36(.31)$ & $404(.46)$ & $\mathbf{4 6 7}(.44)$ \\
\hline $\begin{array}{l}\text { Somewhat } \\
\text { likely }\end{array}$ & $23(.28)$ & $28(.24)$ & $246(.28)$ & $\mathbf{2 9 7}(. \mathbf{2 8})$ \\
\hline Not too likely & $12(.15)$ & $17(.15)$ & $88(.10)$ & $\mathbf{1 1 7}(.11)$ \\
\hline $\begin{array}{l}\text { Not at all } \\
\text { likely }\end{array}$ & $15(.18)$ & $23(.20)$ & $70(.08)$ & $\mathbf{1 0 8}(.10)$ \\
\hline Unsure & $4(.06)$ & $11(.09)$ & $70(.07)$ & $\mathbf{8 5}(\mathbf{. 0 8})$ \\
\hline Total & $\mathbf{8 1}$ & $\mathbf{1 1 5}$ & $\mathbf{8 7 8}$ & $\mathbf{1 0 7 3}$ \\
\hline
\end{tabular}




\section{Table S3.}

Responses by race to the item "When a federally-approved COVID-19 vaccine is available to you, will you..." in the Suffolk-Boston Globe survey.

\begin{tabular}{|l|c|c|c|c|c|}
\hline & Asian & Black & Latinx & White & Total \\
\hline $\begin{array}{l}\text { Take it as soon } \\
\text { as you can? }\end{array}$ & $17(.71)$ & $5(.11)$ & $16(.32)$ & $219(.59)$ & $\mathbf{2 6 1}(. \mathbf{5 2})$ \\
\hline $\begin{array}{l}\text { Wait awhile } \\
\text { until others } \\
\text { have taken it? }\end{array}$ & $7(.29)$ & $24(.55)$ & $21(.42)$ & $107(.29)$ & $\mathbf{1 6 4}(. \mathbf{3 3})$ \\
\hline $\begin{array}{l}\text { Not take the } \\
\text { vaccine? }\end{array}$ & $0(.00)$ & $13(.30)$ & $13(.26)$ & $35(.09)$ & $\mathbf{6 2}(\mathbf{. 1 2})$ \\
\hline Undecided & $0(.00)$ & $2(.05)$ & $0(.00)$ & $10(.03)$ & $\mathbf{1 2}(\mathbf{. 0 2})$ \\
\hline Total & $\mathbf{2 4}$ & $\mathbf{4 4}$ & $\mathbf{5 0}$ & $\mathbf{3 7 2}$ & $\mathbf{5 0 0}$ \\
\hline
\end{tabular}




\section{Table S4.}

Cross-tabs between the items "When an FDA-approved vaccine for COVID is made available, how likely will you be to take it?" and "When an FDA-approved vaccine for COVID is made available, when do you think you will be most likely to take it?" in the Mass Inc.-Museum of Science survey.in the Suffolk-Boston Globe survey.

\begin{tabular}{|l|c|c|c|c|}
\hline & Very Likely & $\begin{array}{c}\text { Somewhat } \\
\text { likely }\end{array}$ & Not too likely & $\begin{array}{c}\text { Not at all } \\
\text { likely }\end{array}$ \\
\hline $\begin{array}{l}\text { As soon as } \\
\text { possible }\end{array}$ & .72 & .13 & .03 & .01 \\
\hline $\begin{array}{l}\text { After a few } \\
\text { people I know } \\
\text { have taken it }\end{array}$ & .18 & .35 & .10 & .01 \\
\hline $\begin{array}{l}\text { After many } \\
\text { other people } \\
\text { have taken it }\end{array}$ & .08 & .45 & .70 & .20 \\
\hline Never & .00 & .00 & .05 & .59 \\
\hline Unsure & .02 & .07 & .12 & .19 \\
\hline
\end{tabular}


Table S5.

Parameter estimates (unstandardized betas, standard errors, and standardized betas) from regression equations meta-analyzing the impacts of different levels of persuasion, vaccine efficacy, and rollout rate on indicators of disparity from across simulations.

\begin{tabular}{|c|c|c|c|c|c|c|c|c|c|c|c|c|}
\hline & \multicolumn{2}{|c|}{ Effect of \% Black } & \multicolumn{2}{|c|}{ Effect of \% Latinx } & \multicolumn{2}{|c|}{$\begin{array}{c}\text { Effect of \% Black } \\
\text { (cont. inf.) }\end{array}$} & \multicolumn{2}{|c|}{$\begin{array}{l}\text { Effect of \% Latinx } \\
\text { (cont. inf.) }\end{array}$} & \multicolumn{2}{|c|}{$\begin{array}{c}\text { Diff. \% Cmmtys w/ } \\
\text { Imm. }\end{array}$} & \multicolumn{2}{|c|}{$\begin{array}{l}\text { Diff. Avg. Date of } \\
\text { Imm. }\end{array}$} \\
\hline & B (s.e.) & $\beta$ & B (s.e.) & $\beta$ & B (s.e.) & $\beta$ & B (s.e.) & $\beta$ & B (s.e.) & $\beta$ & B (s.e.) & $\beta$ \\
\hline Persuasion & $\begin{array}{c}-22.96^{* * *} \\
(1.49)\end{array}$ & -.90 & $\begin{array}{c}-25.99 * * * \\
(4.33)\end{array}$ & -.37 & $\begin{array}{c}-21.74 * * * \\
(1.54)\end{array}$ & -.84 & $\begin{array}{c}-16.93 * * * \\
(1.61)\end{array}$ & -.80 & $\begin{array}{c}-10.69 * * \\
(3.44)\end{array}$ & -.47 & $\begin{array}{c}-396.99 * * * \\
(68.50)\end{array}$ & -.46 \\
\hline $\begin{array}{l}\text { Vaccine } \\
\text { Efficacy }\end{array}$ & $\begin{array}{c}-1.25 * * * \\
(0.27)\end{array}$ & -.27 & $\begin{array}{c}-5.01 * * * \\
(0.77)\end{array}$ & -.41 & $\begin{array}{l}-0.69 * \\
(0.27)\end{array}$ & -.15 & $\begin{array}{c}-0.90 * * \\
(0.29)\end{array}$ & -.24 & $-0.55(0.61)$ & -.14 & $\begin{array}{l}-10.56 \\
(9.43)\end{array}$ & -.09 \\
\hline $\begin{array}{l}\text { Rollout } \\
\text { Rate }^{\mathrm{a}}\end{array}$ & $\begin{array}{c}0.14 \\
(0.09)\end{array}$ & .10 & $\begin{array}{c}-3.00 * * * \\
(0.25)\end{array}$ & -.76 & $\begin{array}{c}0.60 * * * \\
(0.09)\end{array}$ & .41 & $\begin{array}{c}0.41 * * * \\
(0.09)\end{array}$ & .34 & $-0.28(0.20)$ & -.22 & $\begin{array}{c}28.08 * * * \\
(3.06)\end{array}$ & .75 \\
\hline
\end{tabular}

$\mathrm{p}<0.05 ; * * \mathrm{p}<.01 ;{ }^{* * *} \mathrm{p}<0.001$

a - Measured as the percentage of the population that could be vaccinated each day under the assumed length of the rollout, meaning higher values reflect a faster rollout. 


\section{Table S6.}

Comparisons of disparities across all simulations for herd immunity, including the percentage of predominantly White and high Black-Latinx communities that reach herd immunity and the average date of reaching herd immunity.

\begin{tabular}{|c|c|c|c|c|}
\hline & $\begin{array}{l}\text { No Persuasion } \\
\quad(\kappa=0)\end{array}$ & $\begin{array}{c}\text { Low Persuasion } \\
(\kappa=.013)\end{array}$ & $\begin{array}{c}\text { Medium } \\
\text { Persuasion }(\kappa= \\
.026)\end{array}$ & $\begin{array}{l}\text { High Persuasion } \\
(\kappa=.039)\end{array}$ \\
\hline \multicolumn{5}{|c|}{ Distribution Time $=3$ months } \\
\hline $\begin{array}{l}\text { Vaccine Efficacy } \\
=75 \%\end{array}$ & $\begin{array}{c}34 \% \text { vs. } 0 \% \\
139 \text { days vs. NA }\end{array}$ & $\begin{array}{c}100 \% \text { vs. } 18 \% \\
129 \text { days vs. } 178 \\
\text { days } \\
\end{array}$ & $\begin{array}{c}100 \% \text { vs. } 77 \% \\
115 \text { days vs. } 163 \\
\text { days } \\
\end{array}$ & $\begin{array}{c}100 \% \text { vs. } 100 \% \\
109 \text { days vs. } 155 \\
\text { days }\end{array}$ \\
\hline $\begin{array}{l}\text { Vaccine Efficacy } \\
=85 \%\end{array}$ & $\begin{array}{c}80 \% \text { vs. } 0 \% \\
138 \text { days vs. NA }\end{array}$ & $\begin{array}{c}100 \% \text { vs. } 64 \% \\
\begin{array}{c}111 \text { days vs. } 164 \\
\text { days }\end{array} \\
\end{array}$ & $\begin{array}{c}100 \% \text { vs. } 100 \% \\
101 \text { days vs. } 149 \\
\text { days }\end{array}$ & $\begin{array}{l}100 \% \text { vs. } 100 \% \\
97 \text { days vs. } 138 \\
\text { days }\end{array}$ \\
\hline $\begin{array}{l}\text { Vaccine Efficacy } \\
=95 \%\end{array}$ & $\begin{array}{c}97 \% \text { vs. } 0 \% \\
121 \text { days vs. NA }\end{array}$ & $\begin{array}{l}100 \% \text { vs. } 86 \% 99 \\
\text { days vs. } 153 \text { days }\end{array}$ & $\begin{array}{c}100 \% \text { vs. } 100 \% \\
91 \text { days vs. } 134 \\
\text { days }\end{array}$ & $\begin{array}{l}100 \% \text { vs. } 100 \% \\
88 \text { days vs. } 125 \\
\text { days }\end{array}$ \\
\hline \multicolumn{5}{|c|}{ Distribution Time $=4$ months } \\
\hline $\begin{array}{l}\text { Vaccine Efficacy } \\
=75 \%\end{array}$ & $\begin{array}{c}28 \% \text { vs. } 0 \% \\
152 \text { days vs. NA }\end{array}$ & $\begin{array}{c}97 \% \text { vs. } 0 \% \\
142 \text { days vs. NA }\end{array}$ & $\begin{array}{c}100 \% \text { vs. } 59 \% \\
\begin{array}{c}131 \text { days vs. } 171 \\
\text { days }\end{array} \\
\end{array}$ & $\begin{array}{c}100 \% \text { vs. } 86 \% \\
127 \text { days vs. } 166 \\
\text { days } \\
\end{array}$ \\
\hline $\begin{array}{l}\text { Vaccine Efficacy } \\
=85 \%\end{array}$ & $\begin{array}{c}57 \% \text { vs. } 0 \% \\
141 \text { days vs. NA }\end{array}$ & $\begin{array}{c}100 \% \text { vs. } 50 \% \\
125 \text { days vs. } 171 \\
\text { days } \\
\end{array}$ & $\begin{array}{c}100 \% \text { vs. } 100 \% \\
116 \text { days vs. } 159 \\
\text { days } \\
\end{array}$ & $\begin{array}{c}100 \% \text { vs. } 100 \% \\
114 \text { days vs. } 150 \\
\text { days }\end{array}$ \\
\hline $\begin{array}{l}\text { Vaccine Efficacy } \\
=95 \%\end{array}$ & $\begin{array}{c}95 \% \text { vs. } 0 \% \\
135 \text { days vs. NA }\end{array}$ & $\begin{array}{c}100 \% \text { vs. } 82 \% \\
112 \text { days vs. } 160 \\
\text { days } \\
\end{array}$ & $\begin{array}{c}100 \% \text { vs. } 100 \% \\
106 \text { days vs. } 144 \\
\text { days } \\
\end{array}$ & $\begin{array}{c}100 \% \text { vs. } 100 \% \\
104 \text { days vs. } 137 \\
\text { days }\end{array}$ \\
\hline \multicolumn{5}{|c|}{ Distribution Time $=6$ months } \\
\hline $\begin{array}{l}\text { Vaccine Efficacy } \\
=75 \%\end{array}$ & $\begin{array}{c}5 \% \text { vs. } 0 \% \\
169 \text { days vs. NA }\end{array}$ & $\begin{array}{c}45 \% \text { vs. } 0 \% \\
161 \text { days vs. NA }\end{array}$ & $\begin{array}{c}60 \% \text { vs. } 0 \% \\
162 \text { days vs. NA }\end{array}$ & $\begin{array}{c}65 \% \text { vs. } 0 \% \\
163 \text { days vs. NA }\end{array}$ \\
\hline $\begin{array}{l}\text { Vaccine Efficacy } \\
=85 \%\end{array}$ & $\begin{array}{c}28 \% \text { vs. } 0 \% \\
158 \text { days vs. NA }\end{array}$ & $\begin{array}{c}88 \% \text { vs. } 0 \% 157 \\
\text { days vs. NA }\end{array}$ & $\begin{array}{c}95 \% \text { vs. } 18 \% \\
155 \text { days vs. } 179 \\
\text { days }\end{array}$ & $\begin{array}{c}95 \% \text { vs. } 23 \% \\
155 \text { days vs. } 177 \\
\text { days }\end{array}$ \\
\hline $\begin{array}{l}\text { Vaccine Efficacy } \\
=95 \%\end{array}$ & $\begin{array}{c}54 \% \text { vs. } 0 \% \\
150 \text { days vs. NA }\end{array}$ & $\begin{array}{l}98 \% \text { vs. } 32 \% 145 \\
\text { days vs. } 178 \text { days }\end{array}$ & $\begin{array}{c}100 \% \text { vs. } 91 \% \\
144 \text { days vs. } 173 \\
\text { days }\end{array}$ & $\begin{array}{c}100 \% \text { vs. } 95 \% \\
144 \text { days vs. } 171 \\
\text { days }\end{array}$ \\
\hline
\end{tabular}




\section{Table S7.}

Comparisons of disparities across all simulations for infection rates, including the regression parameters for percentage Black and percentage Latinx, with and without controlling for infection rates under the no-vaccine scenario.

\begin{tabular}{|c|c|c|c|c|}
\hline & $\begin{array}{l}\text { No Persuasion } \\
\quad(\kappa=0)\end{array}$ & $\begin{array}{c}\text { Low Persuasion } \\
(\kappa=.013)\end{array}$ & $\begin{array}{l}\text { Medium } \\
\text { Persuasion } \\
(\kappa=.026)\end{array}$ & $\begin{array}{c}\text { High Persuasion } \\
(\kappa=.039)\end{array}$ \\
\hline \multicolumn{5}{|c|}{ Distribution Time $=3$ months } \\
\hline $\begin{array}{l}\text { Vaccine Efficacy } \\
=75 \%\end{array}$ & $\begin{array}{c}\% \text { Black }=1.44 \\
\% \text { Latinx }=2.63 \\
\% \text { Black (cont. } \\
\text { inf.) }=1.25 \\
\% \text { Latinx (cont. } \\
\text { inf.) }=1.22\end{array}$ & $\begin{array}{c}\% \text { Black }=0.90 \\
\% \text { Latinx }=1.70 \\
\% \text { Black (cont. } \\
\text { inf.) }=0.77 \\
\% \text { Latinx (cont. } \\
\text { inf.) }=0.76\end{array}$ & $\begin{array}{c}\% \text { Black }=0.54 \\
\% \text { Latinx }=1.18 \\
\% \text { Black (cont. } \\
\text { inf.) }=0.45 \\
\% \text { Latinx (cont. } \\
\text { inf.) }=0.47\end{array}$ & $\begin{array}{c}\% \text { Black }=0.33 \\
\% \text { Latinx }=0.91 \\
\% \text { Black (cont. } \\
\text { inf.) }=0.25 \\
\% \text { Latinx (cont. } \\
\text { inf.) }=0.30\end{array}$ \\
\hline $\begin{array}{l}\text { Vaccine Efficacy } \\
=85 \%\end{array}$ & $\begin{array}{c}\% \text { Black }=1.21 \\
\% \text { Latinx }=2.00 \\
\% \text { Black (cont. } \\
\text { inf. })=1.08 \\
\% \text { Latinx (cont. } \\
\text { inf.) }=1.01\end{array}$ & $\begin{array}{c}\% \text { Black }=0.72 \\
\% \text { Latinx }=1.21 \\
\% \text { Black (cont. } \\
\text { inf.) }=0.63 \\
\% \text { Latinx (cont. } \\
\text { inf.) }=0.60\end{array}$ & $\begin{array}{c}\% \text { Black }=0.41 \\
\% \text { Latinx }=0.80 \\
\% \text { Black (cont. } \\
\text { inf.) }=0.35 \\
\% \text { Latinx (cont. } \\
\text { inf.) }=0.35\end{array}$ & $\begin{array}{c}\% \text { Black }=0.24 \\
\% \text { Latinx }=0.60 \\
\% \text { Black (cont. } \\
\text { inf.) }=0.19 \\
\% \text { Latinx (cont. } \\
\text { inf.) }=0.22\end{array}$ \\
\hline $\begin{array}{l}\text { Vaccine Efficacy } \\
=95 \%\end{array}$ & $\begin{array}{c}\% \text { Black }=1.01 \\
\% \text { Latinx }=1.52 \\
\% \text { Black (cont. } \\
\text { inf.) }=0.92 \\
\% \text { Latinx (cont. } \\
\text { inf.) }=0.83\end{array}$ & $\begin{array}{c}\% \text { Black }=0.56 \\
\% \text { Latinx }=0.87 \\
\% \text { Black (cont. } \\
\text { inf.) }=0.51 \\
\% \text { Latinx (cont. } \\
\text { inf.) }=0.46\end{array}$ & $\begin{array}{c}\text { \% Black }=0.30 \\
\% \text { Latinx }=0.54 \\
\% \text { Black (cont. } \\
\text { inf.) }=0.26 \\
\% \text { Latinx (cont. } \\
\text { inf.) }=0.26\end{array}$ & $\begin{array}{c}\% \text { Black }=0.17 \\
\% \text { Latinx }=0.39 \\
\% \text { Black (cont. } \\
\text { inf.) }=0.14 \\
\% \text { Latinx (cont. } \\
\text { inf.) }=0.16\end{array}$ \\
\hline \multicolumn{5}{|c|}{ Distribution Time $=4$ months } \\
\hline $\begin{array}{l}\text { Vaccine Efficacy } \\
=75 \%\end{array}$ & $\begin{array}{c}\% \text { Black }=1.43 \\
\% \text { Latinx }=2.99 \\
\% \text { Black (cont. } \\
\text { inf.) }=1.19 \\
\% \text { Latinx (cont. } \\
\text { inf.) }=1.18\end{array}$ & $\begin{array}{c}\% \text { Black }=0.90 \\
\% \text { Latinx }=2.09 \\
\% \text { Black (cont. } \\
\text { inf.) }=0.71 \\
\% \text { Latinx (cont. } \\
\text { inf.) }=0.71\end{array}$ & $\begin{array}{c}\% \text { Black }=0.51 \\
\% \text { Latinx }=1.60 \\
\% \text { Black (cont. } \\
\text { inf.) }=0.34 \\
\% \text { Latinx (cont. } \\
\text { inf.) }=0.38\end{array}$ & $\begin{array}{c}\% \text { Black }=0.28 \\
\% \text { Latinx }=1.39 \\
\% \text { Black (cont. } \\
\text { inf.) }=0.12 \\
\% \text { Latinx (cont. } \\
\text { inf.) }=0.19\end{array}$ \\
\hline $\begin{array}{l}\text { Vaccine Efficacy } \\
=85 \%\end{array}$ & $\begin{array}{c}\% \text { Black }=1.23 \\
\% \text { Latinx }=2.32 \\
\% \text { Black (cont. } \\
\text { inf.) }=1.05 \\
\% \text { Latinx (cont. } \\
\text { inf.) }=1.00\end{array}$ & $\begin{array}{c}\% \text { Black }=0.73 \\
\% \text { Latinx }=1.55 \\
\% \text { Black (cont. } \\
\text { inf.) }=0.60 \\
\% \text { Latinx (cont. } \\
\text { inf.) }=0.58\end{array}$ & $\begin{array}{c}\% \text { Black }=0.39 \\
\% \text { Latinx }=1.14 \\
\% \text { Black (cont. } \\
\text { inf.) }=0.28 \\
\% \text { Latinx (cont. } \\
\text { inf.) }=0.30\end{array}$ & $\begin{array}{c}\% \text { Black }=0.20 \\
\% \text { Latinx }=0.97 \\
\% \text { Black (cont. } \\
\text { inf.) }=0.09 \\
\% \text { Latinx (cont. } \\
\text { inf.) }=0.15\end{array}$ \\
\hline $\begin{array}{l}\text { Vaccine Efficacy } \\
=95 \%\end{array}$ & $\begin{array}{c}\% \text { Black }=1.04 \\
\% \text { Latinx }=1.79 \\
\% \text { Black (cont. } \\
\text { inf.) }=0.91\end{array}$ & $\begin{array}{c}\% \text { Black }=0.59 \\
\% \text { Latinx }=1.14 \\
\% \text { Black (cont. } \\
\text { inf.) }=0.50\end{array}$ & $\begin{array}{c}\% \text { Black }=0.30 \\
\% \text { Latinx }=0.81 \\
\% \text { Black (cont. } \\
\text { inf.) }=0.23\end{array}$ & $\begin{array}{c}\% \text { Black }=0.15 \\
\% \text { Latinx }=0.68 \\
\% \text { Black (cont. } \\
\text { inf.) }=0.07\end{array}$ \\
\hline
\end{tabular}




\begin{tabular}{|c|c|c|c|c|}
\hline & $\begin{array}{c}\% \text { Latinx (cont. } \\
\text { inf.) }=0.84\end{array}$ & $\begin{array}{c}\text { \% Latinx (cont. } \\
\text { inf.) }=0.47\end{array}$ & $\begin{array}{c}\% \text { Latinx (cont. } \\
\text { inf.) }=0.23\end{array}$ & $\begin{array}{c}\% \text { Latinx (cont. } \\
\text { inf.) }=0.11\end{array}$ \\
\hline \multicolumn{5}{|c|}{ Distribution Time $=6$ months } \\
\hline $\begin{array}{l}\text { Vaccine Efficacy } \\
=75 \%\end{array}$ & $\begin{array}{c}\text { \% Black }=1.20 \\
\% \text { Latinx }=4.00 \\
\% \text { Black (cont. } \\
\text { inf.) }=0.75 \\
\% \text { Latinx (cont. } \\
\text { inf.) }=0.64\end{array}$ & $\begin{array}{c}\text { \% Black }=0.62 \\
\% \text { Latinx }=3.61 \\
\% \text { Black (cont. } \\
\text { inf.) }=0.16 \\
\% \text { Latinx (cont. } \\
\text { inf.) }=0.23\end{array}$ & $\begin{array}{c}\text { \% Black }=0.43 \\
\% \text { Latinx }=3.63 \\
\% \text { Black (cont. } \\
\text { inf.) }=-0.03 \\
\% \text { Latinx (cont. } \\
\text { inf.) }=0.23\end{array}$ & $\begin{array}{c}\% \text { Black }=0.43 \\
\% \text { Latinx }=3.63 \\
\% \text { Black (cont. } \\
\text { inf.) }=-0.03 \\
\% \text { Latinx (cont. } \\
\text { inf.) }=0.23\end{array}$ \\
\hline $\begin{array}{l}\text { Vaccine Efficacy } \\
=85 \%\end{array}$ & $\begin{array}{c}\% \text { Black }=1.05 \\
\% \text { Latinx }=3.25 \\
\% \text { Black (cont. } \\
\text { inf.) }=0.69 \\
\% \text { Latinx (cont. } \\
\text { inf.) }=0.58\end{array}$ & $\begin{array}{c}\text { \% Black }=0.51 \\
\% \text { Latinx }=2.90 \\
\% \text { Black (cont. } \\
\text { inf.) }=0.15 \\
\% \text { Latinx (cont. } \\
\text { inf.) }=0.21\end{array}$ & $\begin{array}{c}\% \text { Black }=0.34 \\
\% \text { Latinx }=2.91 \\
\% \text { Black (cont. } \\
\text { inf.) }=-0.03 \\
\% \text { Latinx (cont. } \\
\text { inf.) }=0.21\end{array}$ & $\begin{array}{c}\text { \% Black }=0.34 \\
\% \text { Latinx }=2.91 \\
\% \text { Black (cont. } \\
\text { inf.) }=-0.03 \\
\% \text { Latinx (cont. } \\
\text { inf.) }=0.21\end{array}$ \\
\hline $\begin{array}{l}\text { Vaccine Efficacy } \\
=95 \%\end{array}$ & $\begin{array}{c}\% \text { Black }=0.92 \\
\% \text { Latinx }=2.64 \\
\% \text { Black (cont. } \\
\text { inf.) }=0.63 \\
\% \text { Latinx (cont. } \\
\text { inf.) }=0.52\end{array}$ & $\begin{array}{c}\% \text { Black }=0.42 \\
\% \text { Latinx }=2.32 \\
\% \text { Black (cont. } \\
\text { inf. })=0.13 \\
\% \text { Latinx (cont. } \\
\text { inf.) }=0.18\end{array}$ & $\begin{array}{c}\% \text { Black }=0.27 \\
\% \text { Latinx }=2.33 \\
\% \text { Black (cont. } \\
\text { inf.) }=-0.02 \\
\% \text { Latinx (cont. } \\
\text { inf.) }=0.18\end{array}$ & $\begin{array}{c}\% \text { Black }=0.27 \\
\% \text { Latinx }=2.33 \\
\% \text { Black (cont. } \\
\text { inf.) }=-0.02 \\
\% \text { Latinx (cont. } \\
\text { inf.) }=0.18\end{array}$ \\
\hline
\end{tabular}


Figures

A

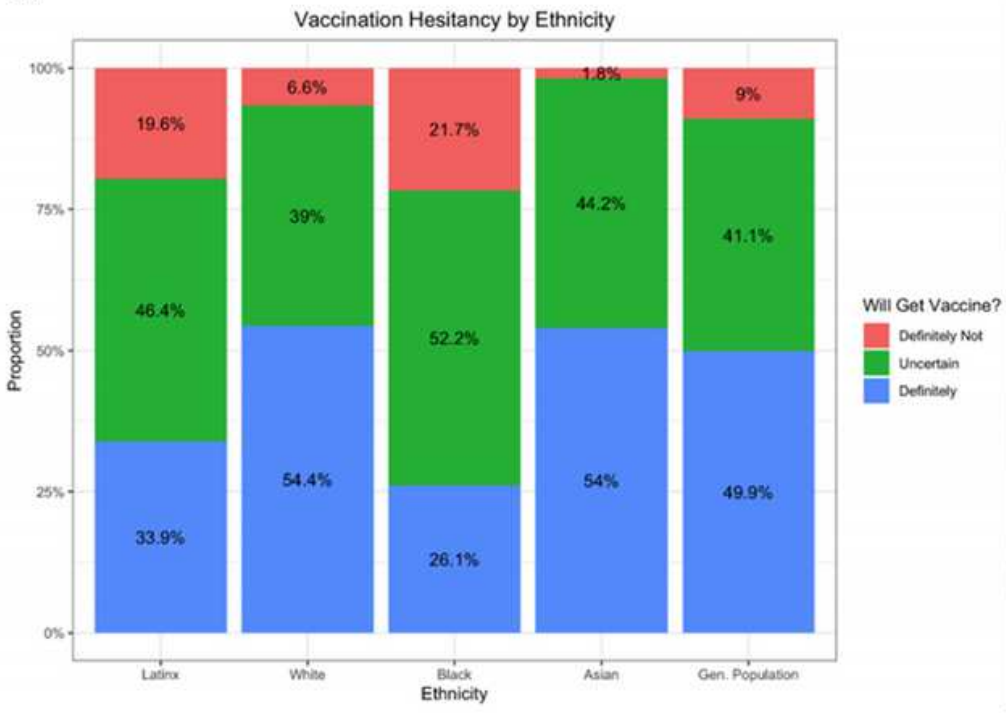

B

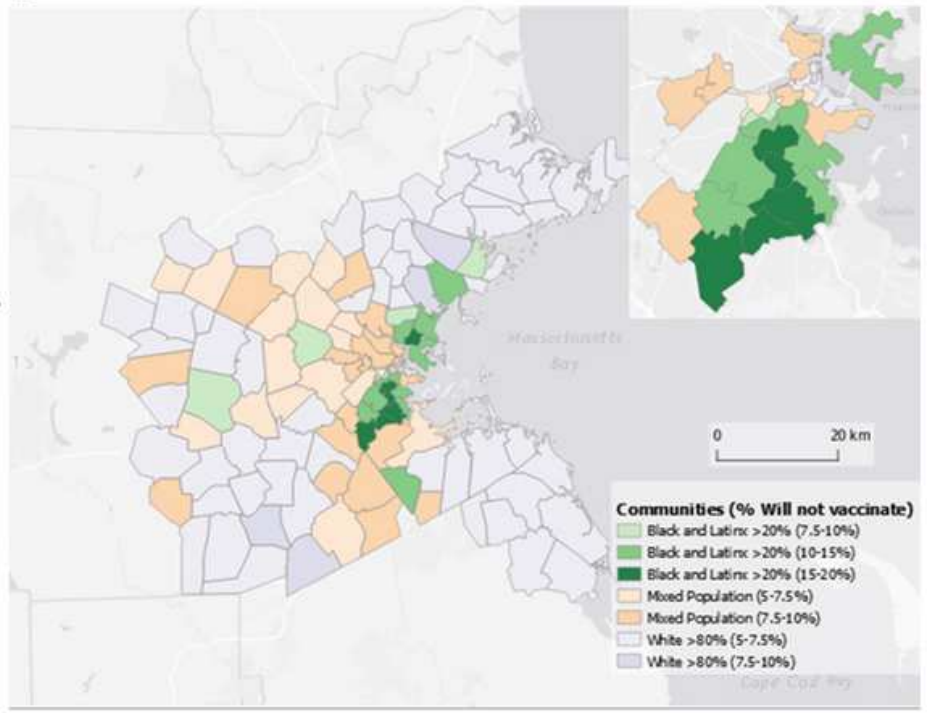

\section{Figure 1}

Representation of variations in vaccine intentions. (A) Individuals vary in their intentions to receive the vaccine by ethnicity. When combined with $(B)$ the categorization of communities by predominantly White $(>80 \%)$, high Black-Latinx $(>20 \%)$, or other, these disparities translate into geographic differences in the proportion who definitely will not vaccinate.
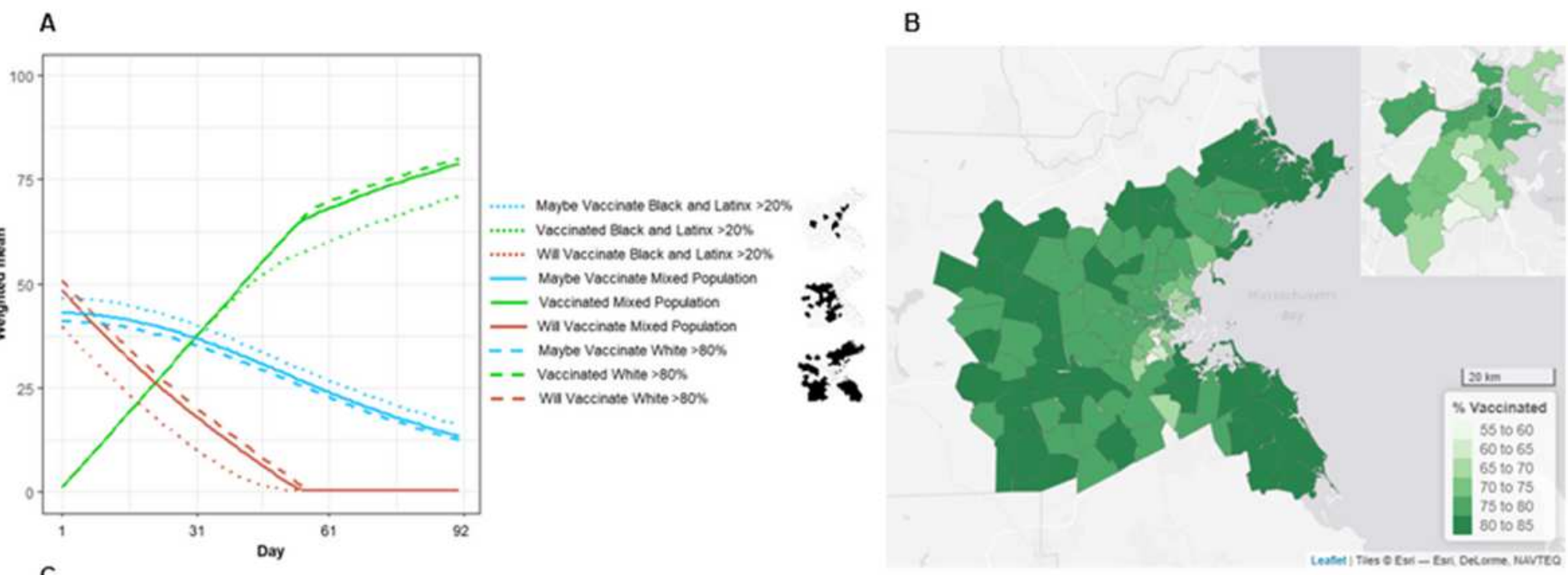

C

Black and Latinx $>20 \%$

Mixed Population

White $>80 \%$

\%Vaccinated \%Will Vaccinate \%Maybe Vaccinate \%Vaccinated \%Will Vaccinate \%Maybe Vaccinate \%Vaccinated \%Will Vaccinate \%Maybe Vaccinate

\begin{tabular}{|c|c|c|c|c|c|c|c|c|c|}
\hline Min & 58.57 & 0.28 & 13.7 & 76.62 & 0.27 & 12.8 & 78.22 & 0.26 & 12.08 \\
\hline $\operatorname{Max}$ & 77.2 & 0.33 & 21.34 & 81.1 & 0.29 & 14.3 & 80.99 & 0.3 & 14.38 \\
\hline Mean & 70.41 & 0.3 & 16.36 & 78.93 & 0.28 & 13.39 & 80.12 & 0.27 & 12.65 \\
\hline Median & 71.75 & 0.3 & 15.74 & 78.94 & 0.28 & 13.29 & 80.23 & 0.27 & 12.67 \\
\hline Range & $58.57-77.20$ & $0.28-0.33$ & $13.70-21.34$ & $76.62-81.10$ & $0.27-0.29$ & $12.80-14.30$ & $78.22-80.99$ & $0.26-0.30$ & $12.08-14.38$ \\
\hline
\end{tabular}

\section{Figure 2}


Vaccination rates varied across communities throughout the simulation. (A) Growth curves of the percentage of residents intending to vaccinate, will maybe vaccinate, and have been vaccinated across the three-month simulation, broken out by communities that are predominantly White, high Black-Latinx, and other. These different curves resulted in disparities across communities in (B) the total percentage of those vaccinated at the end of the simulation. (C) shows the disparities at the end of the modeling process.

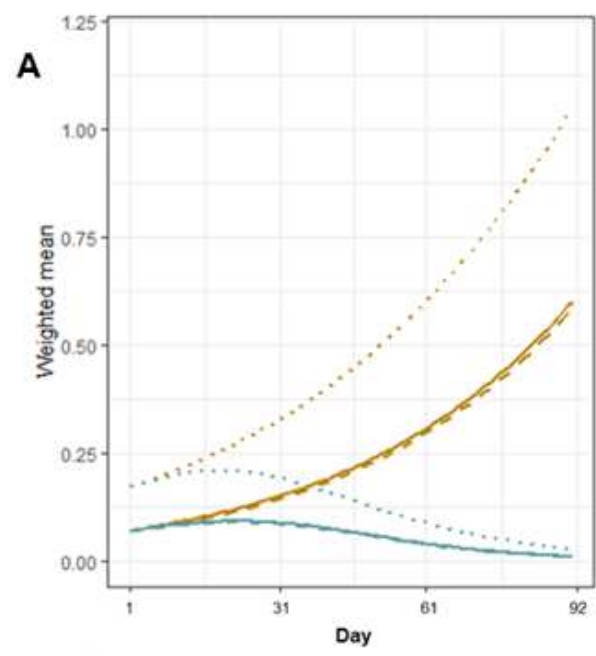

...... Infected w/o vaccination Black and Latin $x>20 \%$ Infected $w /$ vaccination Black and Latin $x>20 \%$

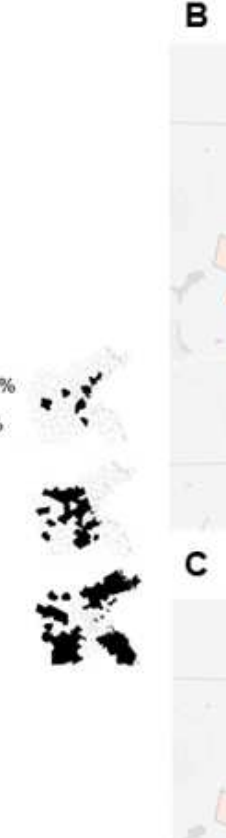

- Infected w/o vaccination Mixed Population

Infected w/ vaccination Mixed Population

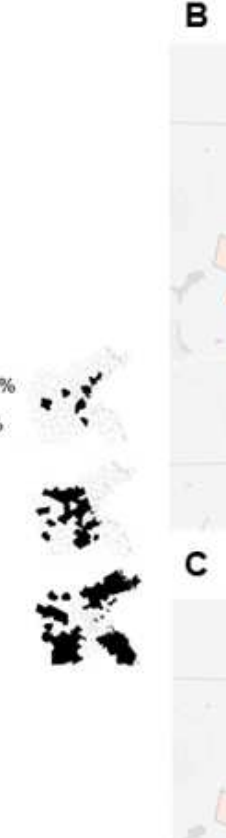

B

Infected w/o vaccination White $>80 \%$ Infected $w /$ vaccination White $>80 \%$
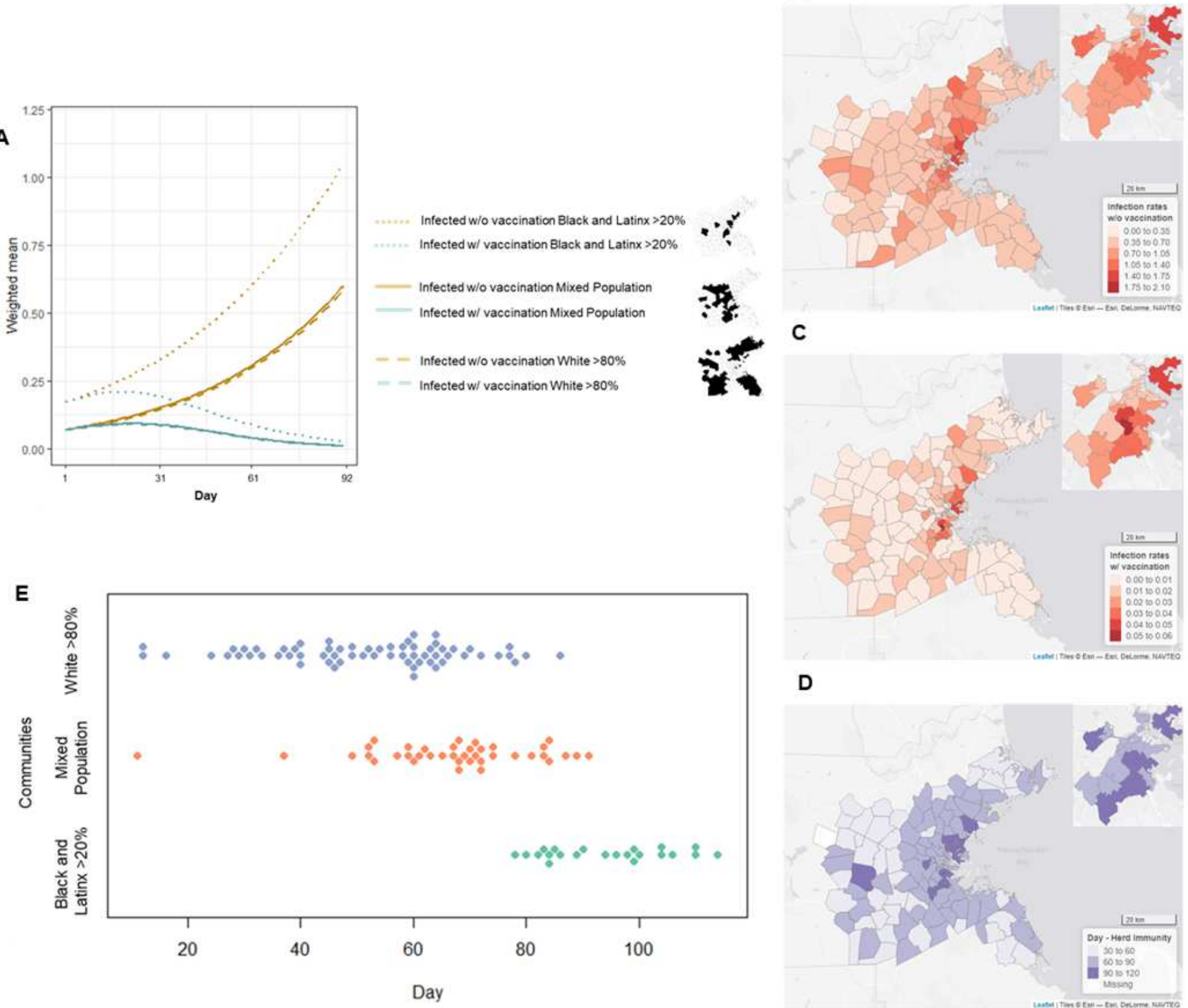

D

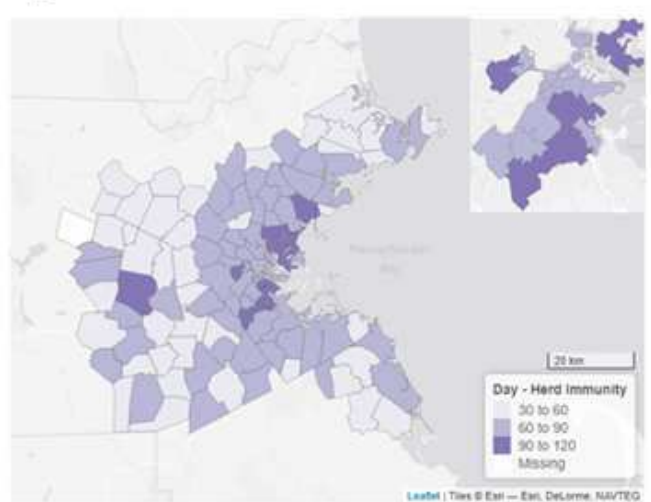

Figure 3

Vaccination rates varied across communities throughout the simulation. (A) Growth curves of the percentage of residents intending to vaccinate, will maybe vaccinate, and have been vaccinated across the three-month simulation, broken out by communities that are predominantly White, high Black-Latinx, and other. These different curves resulted in disparities across communities in (B) the total percentage of 
those vaccinated at the end of the simulation. (C) shows the disparities at the end of the modeling process. (D) shows the day when heard immunity is reached per communities on the map, while (E) shows a graphic representation of when communities reach herd immunity.

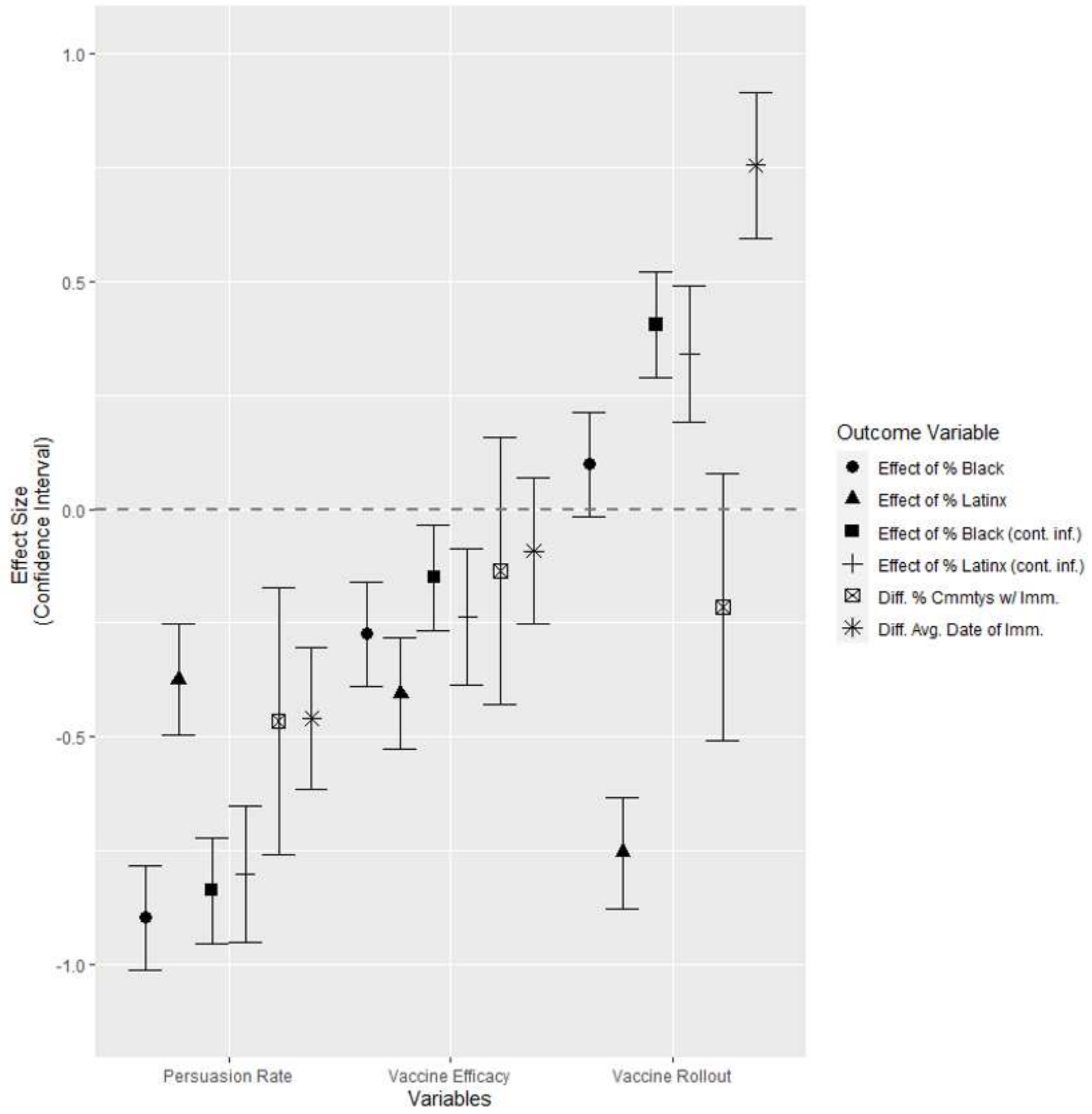

Figure 4

Disparity across simulations. Parameter estimates (unstandardized betas, standard errors, and standardized betas) from regression equations meta-analyzing the indicators of disparity from across 
simulations with different levels of persuasion, vaccine efficacy, and rollout rate. 